\title{
Der Wohlfahrtsstaat in der Krise? Eine Bilanz nach drei Jahrzehnten Sozialpolitik in der Bundesrepublik*
}

\author{
Jens/Alber \\ Europaisches Hochschulinstitut, Abteilung Politik und Gesellschaftswissenschaften \\ Badia Fiesolana, Via dei Roccettini, I-50016 San Domenico di Fiesole (Firenze), Italien
}

\begin{abstract}
$\mathrm{Z}$ u s a m m e $\mathrm{n} f$ a s s u $\mathrm{n}$ : Der Aufsatz beschreibt und analysiert die Entwicklung der Sozialausgaben in der Bundesrepublik von 1949 bis 1978 . Der beschreibende Teil charakterisiert die einzelnen sozialpolitischen Programme anhand der wichtigsten gesetzlichen Veränderungen sowie anhand quantitativer Indikatoren ihrer Leistungen. Der analytische Teil untersucht einige Grundlagen und Konsequenzen der sozialpolitischen Expansion. Zunächst wird die Entwicklung der Sozialleistungsquote in Abhängigkeit vom Wirtschaftswachstum, von der parteipolitischen Zusammensetzung der Regierung und vom Wahlzyklus analysiert. Der Zusammenhang zwischen wirtschaftlichem Wachstum und Sozialleistungssteigerungen ist nur schwach $(r=.18)$. Unter der sozialliberalen Koalition wuchsen die Ausgaben relativ stetig, während sie in der Regierungszeit der CDU in Wahljahren sprunghaft anstiegen. Konsequenzen der sozialpolitischen Expansion werden bezüglich der volkswirtschaftlichen Investitionen, der öffentlichen Verschuldung und der Inflationsrate untersucht. In allen drei Fällen ergibt die bivariate Korrelationsanalyse nur schwache Zusammenhänge $(r=-.23, .32, .15$ in der genannten Reihenfolge). Um der Frage nachzugehen, ob der Wohlfahrtsstaat von einem Element der Integration zunehmend zu einem politischen Spalter wird, werden abschließend einige Umfragedaten zur Einschätzung des Wohlfahrtsstaats in der Bevölkerung sowie die konkurrierenden sozialpolitischen Konzeptionen sozialwissenschaftlicher und politischer Meinungsführer geschildert. Die Untersuchung gibt zwar einige Hinweise auf wachsende sozialpolitische Probleme und eine zunehmende Uneinigkeit über die adäquaten Lösungen, aber überzeugende Symptome einer „Krise“ ließen sich nicht finden.
\end{abstract}

\section{Einleitung}

Nach einer Periode des ungestümen Wachstums, das allseits begrüßt oder zumindest widerspruchslos akzeptiert wurde, ist der Wohlfahrtsstaat zunehmend ins Kreuzfeuer der Kritik geraten. Politiker, die lange Zeit eine hohe Sozialleistungsquote ihres Landes im internationalen Vergleich stolz als Gütezeichen ihrer Politik präsentierten, sprechen neuerdings lieber von den ,Grenzen der Belastbarkeit" oder vom ,Wildwuchs der Sozialleistungen". Sozialwissenschaftler entdecken Anzeichen eines wachsenden Unwillens der Bürger, das kostspielige System der sozialen Sicherung $\mathrm{zu}$ finanzieren, und diagnostizieren einen "welfare backlash" (Wilensky 1975, 1976, 1980). Führende Presseorgane - in Deutschland etwa Die Zeit oder Der Spiegel - veröffentlichen Serien, die sich mit der Krise der europäischen Wohlfahrtsstaaten beschäftigen. Das Bewußtsein einer Krise der Sozialpolitik scheint Vertretern der unterschiedlichsten politischen Richtungen heute gemeinsam.

Fragt man, worin denn die Krise besteht, so ergeben sich allerdings unterschiedliche Antworten. Die konservative Kritik beschwört das gestörte Verhältnis zwischen ökonomischen Ressourcen und sozialpolitischen Kosten und empfiehlt Leistungskürzungen oder Einsparungen durch die Privatisierung sozialer Dienste. Die progressive
Kritik thematisiert dagegen vorwiegend das Ungleichgewicht zwischen Bedürfnissen und mangelhaften Leistungen und fordert stärkere staatliche Umverteilungsmaßnahmen sowie eine Ausdehnung der präventiven, sozialplanerischen Staatsaktivitäten. In einer politisch schwieriger zu verortenden Kritik treffen sich ,Alte Rechte" und „Neue Linke“, die auf das gefährdete Selbsthilfepotential intermediärer Gruppen und die unzureichenden Partizipationschancen der Bürger im Rahmen einer zunehmend bürokratisierten und verrechtlichten Sozialpolitik verweisen. Die Auseinandersetzungen werden auf politischem wie auf sozialwissenschaftlichem Terrain geführt, wobei das Florett wissenschaftlicher Argumentation häufig auch von Sozialwissenschaftlern durch den Säbel politischer Parolen ersetzt wird. Fast immer ist der Bekennermut stärker als die empirische Fundierung der Argumente. Popu-

* Eine englische Fassung dieses Aufsatzes diente als Unterlage für die Arbeitsgruppe „A Crisis of the European Welfare States" im Rahmen der diesjährigen ECPR Joint Sessions of Workshop in Florenz. Der Aufsatz wurde mit Hilfe des im HIWED-Projekt mit Unterstützung der Stiftung Volkswagenwerk archivierten Materials geschrieben. Meinen früheren Kollegen im HIWED Projekt, insbesondere Richard C. Eichenberg, Jürgen Kohl, Franz Kraus und Kurt Seebohm, bin ich für ihre tatkräftige Unterstützung dankbar. Vielfältige Anregungen verdanke ich dem Projektleiter Peter Flora. 
läre Thesen wie die, daß hohe Sozialleistungen Arbeitsbereitschaft und Sparwillen der Bürger schwächen oder daß die Inflation der Ansprüche - bzw. alternativ: der Kapitalismus - dem Wachstum der Sozialausgaben zugrundeliegt, sind nun einmal leichter formuliert und, ungeachtet ihres geringen Originalitätsgrades, in politische Achtungserfolge umgemünzt als durch sozialwissenschaftliche Analysen empirisch gestützt.

Dieser Aufsatz möchte zur empirischen Fundierung der wissenschaftlichen Debatten beitragen. Sein erster Teil beschreibt die Dimensionen des bundesrepublikanischen Wohlfahrtsstaates ${ }^{1}$ und kennzeichnet die Hauptphasen und -trends seiner Entwicklung, wozu neben quantitativen $\mathrm{Da}$ ten auch qualitative Merkmale institutioneller Veränderungen herangezogen werden. Der zweite Teil analysiert, ausgehend von gegenwärtig populären Thesen, einige Determinanten des Wachstums der Sozialleistungen. Der dritte Teil untersucht Begleiterscheinungen und Konsequen zen der sozialpolitischen Ausdehnung unter Bezug auf momentan kursierende Krisentheoreme. Der abschließende vierte Teil verbindet eine resümierende Einschätzung des Realitätsgehalts der Krisenvorstellungen mit einem kurzen Ausblick auf die künftigen Wachstumschancen des deutschen Wohlfahrtsstaates.

\section{Charakteristika des Wohlfahrtsstaates in der Bundesrepublik}

\section{(1) Dimensionen und Grundzüge der bundesre- publikanischen Sozialpolitik}

Nach der totalen Niederlage des ,Dritten Reiches" sahen die Pläne der Alliierten Kontrollkommission zunächst eine grundlegende Umstrukturierung der deutschen Sozialleistungen vor, in teilweiser Anlehnung an das nach dem Zweiten Weltkrieg in der westlichen Welt weit diskutierte britische Reformmodell einer einheitlichen Staatsbürgerversicherung nach Beveridge.

1 Abweichend vom populären deutschen Sprachgebrauch, der zwischen einem positiv einzuschätzenden demokratischen "Sozialstaat" und einem bürgerliche Freiheiten bedrohenden „Wohlfahrtsstaat" unterscheidet, wird der sich in der internationalen Literatur immer mehr durchsetzende Begriff , Wohlfahrtsstaat" hier synonym mit den deutschen Begriffen ,Sozialstaat" oder „Sozialpolitik" verwendet.
In den westlichen Besatzungszonen wurden diese Pläne jedoch nur ansatzweise in regional begrenztem Rahmen (Berlin, Bremen) realisiert. Im Zeichen des beginnenden Ost-West-Konflikts und des Widerstands deutscher Interessengruppen gegen eine grundlegende Neuordnung wurden die Weichen bald fur eine Restauration der tradtionellen deutschen Sozialpolitik gestellt, wie sie vor der Zäsur des Hitler-Regimes bestanden hatte. Konstitutive Elemente dieser Politik sind drei Säulen: (1) die prinzipielle Anerkennung der Freiheit des Arbeitsmarktes mit der Garantie von Vereinigungsfreiheit und Tarifautonomie; (2) die staatliche Angleichung der Machtposition der Arbeitsvertragsparteien durch arbeitsrechtliche Rahmenrichtlinien; (3) die Ergänzung arbeitsvertraglicher Vereinbarungen durch ein staatlich verordnetes, nach kausalen Kriterien gegliedertes und durch teilautonome Körperschaften des öffentlichen Rechts verwaltetes System sozialer Transferzahlungen. Neben die traditionellen Sozialleistungen trat in der Nachkriegszeit eine Vielfalt ergänzender finanz- und wirtschaftspolitischer Maßnahmen, die eine eindeutige Abgrenzung des Bereichs der Sozialpolitik gegenüber anderen Politikbereichen zunehmend schwierig macht. Die in letzter Zeit häufigere Ersetzung des deutschen Begriffs ,,Sozialpolitik" durch den wohl umfassenderen, aber auch diffuseren, angelsächsischen Terminus „Wohlfahrtsstaat" spiegelt diesen Wandel m.E. wider.

Die Übersicht 1 versucht, einen zusammenfassenden Uberblick über die Dimensionen des Wohlfahrtsstaates in der Bundesrepublik mit einer pragmatischen Eingrenzung eines Kernbereichs sozialpolitischer Maßnahmen zu verbinden ${ }^{2}$. Der (umrandete) Kern des Wohlfahrtsstaates besteht demnach aus den diversen Programmen zur Sicherung bzw. Ergänzung der Einkommen, die von der Kriegsopferversorgung bis zur Vermögensbildung reichen und heute etwa ein Viertel des Sozialprodukts beanspruchen. Den finanziellen Löwenanteil unter diesen Programmen beanspruchen die vier Sozialversicherungen, die historisch die Entwicklung des deutschen Wohlfahrtsstaates einleiteten und noch heute sein institutionelles Rückgrat darstellen. Die auf die

2 Für einen systematischeren Versuch der theoretischen Charakterisierung der Grundzüge des Wohtfahrtsstaates vgl. Flora et al. 1977. 
ÜBERSICHT 1: Dimensionen des Wohlfahrtsstaats in der Bundesrepublik

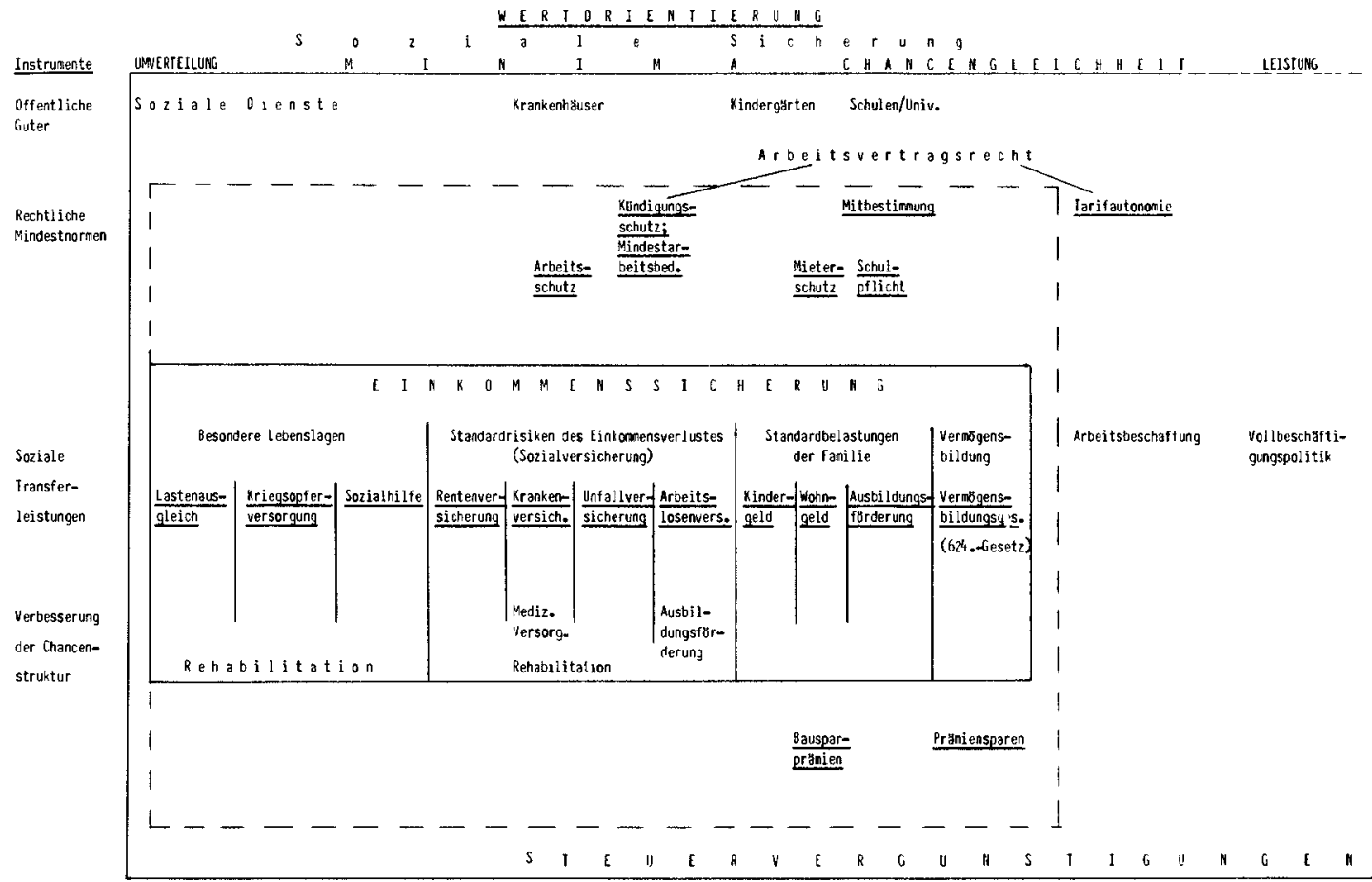

Private Giter

Sicherung der Erwerbsbevölkerung gegen einige Standardrisiken des Einkommensverlustes abzielenden Sozialversicherungen sind ergänzt durch Leistungssysteme für schwerer standardisierbare, außergewöhnliche Belastungen: die Sozialhilfe, der Lastenausgleich für Kriegsfolgelasten der Zivilbevölkerung und die Kriegsopferversorgung für die aktiven Kriegsteilnehmer und ihre Angehörigen. Drei weitere Programme unterstützen die Leistungskraft der Familie: Erziehungsbeihilfen in Form von Kindergeld und Ausbildungsförderung sowie Wohngeld zur Sicherung adäquater Behausung. Seit den sechziger Jahren steht den Einkommenssicherungsprogrammen noch die Förderung der Vermögensbildung zur Seite. Die diversen monetären Leistungssysteme sind häufig durch Sachleistungen ergänzt, die primär auf eine Stärkung der Fähigkeit zur Selbsthilfe abzielen - so die diversen Maßnahmen zur Rehabilitation, zur Gesundheitsförderung und zur Berufsbildung.
Um diese Kernprogramme zur sozialen Sicherung im engeren Sinn $^{3}$ gruppiert sich ein Bündel von rechts- und wirtschaftspolitischen Maßnahmen mit sozialpolitischer Wirkung. Regulative

3 Im internationalen Sprachgebrauch haben sich dafür die Begriffe ,,social security" bzw. ,securité sociale" eingebürgert, wobei die von verschiedenen Organisationen wie EG, OECD, I.L.O., Statistisches Sekretariat der Nordischen Länder etc. verwendeten Abgrenzungen leicht variieren, so daß die berichteten Sozialleistungsquoten einander nicht immer entsprechen. Während z.B. das Internationale Arbeitsamt (abgek. I.L.O.) seine Statistiken auf die Programme im umrandeten Kern bis zum Kindergeld (inkl.) bezieht, haben die umfassenderen Angaben des Bundesarbeitsministeriums über ,direkte Zahlungen" alle umrandeten Programme sowie einige kleinere zusätzliche Ausgabeposten wie Jugendhilfe zum Gegenstand. Die Regierungszahlen über die gesamten Sozialausgaben umfassen darüber hinaus indirekte Leistungen und Arbeitgeberzahlungen so insbesondere die in den I.L.O.-Statistiken 
Eingriffe in das Arbeitsverhältnis - Arbeits- und Gewerbegesetzgebung - und in das Mietverhält. nis - Mieterschutz - geben durch die Fixierung rechtlicher Mindest- oder Rahmennormen der formalen Rechtsgleichheit der vertragsschließenden Parteien sozialen Gehalt. Herausragendstes Beispiel dieser Gesetzgebung sind die bis auf das Betriebsrätegesetz von 1920 zurückgehenden Mitbestimmungsgesetze. $\mathrm{Zu}$ den sozialpolitischen Instrumenten des Staates zählt ferner die Steuerpolitik mit ihren diversen Subventionen und Abschreibungsmöglichkeiten. Wo die Subventionen in Form von Prämien auf private Sparleistungen gegeben werden, sind Ausmaß und Verteilungseffekt zwar relativ gut zu schätzen, aber als breit gestreute Leistungen mit „Gießkannen”Charakter gehören auch sie eher zu den Randbezirken des Wohlfahrtsstaates. Auch öffentliche Güter sind in der Übersicht diesen Randbezirken zugeordnet, da sie zwar den Zugang zu Gütern eröffnen, die sonst den niedrigeren Einkommensgruppen gewöhnlich vorenthalten blieben, aber die Leistungen nicht direkt transferieren, so daß ihre Inanspruchnahme im Ungewissen bleibt. Lediglich die Schulpflicht steht hier dem Kern des Wohlfahrtsstaates näher, denn ihre Ausdehnung eröffnet nicht nur Zugangschancen, sondern impliziert eine effektive Anhebung des Mindeststandards, unter die kein Staatsbürger fallen darf.

Als Leitmotiv der bundesrepublikanischen Sozialpolitik läßt sich die Idee der sozialen Sicherheit bezeichnen, die auf eine Sicherung des vom Bürger erreichten sozialen Status gegen die Risiken sozialen Abstiegs abzielt. Dieser leitenden Wertvorstellung dienen drei grundlegende sozialpolitische Strategien: a) die Garantie eines minimalen - mit der Wirtschaftsentwicklung aber steigenden - Versorgungsstandards als untere Grenze des möglichen Abstiegs, b) die Zahlung einkommensbezogener Sozialleistungen, die den relativen Status im Marktsystem in das System der Transferzahlungen übertragen, $c$ ) die Eröffnung sozialer Aufstiegschancen durch die Förde-

nicht enthaltene Lohnfortzahlung im Krankheitsfall. Nicht in der Übersicht enthalten sind die in der deutschen Literatur traditionell nicht der Sozialpolitik zugerechneten Leistungen für Beamte, die in beiden statistischen Quellen mitberichtet werden. Diese Leistungen beliefen sich 1978 auf ca. $39 \mathrm{Mrd}$. DM, wozu noch etwa 4 Mrd. DM an - nicht in den I.L.O.-Statistiken enthaltenen - Beihilfen $\mathrm{zu}$ rechnen wären. rung der Chancengleichheit. Gleichheit im Sinne der vertikalen Umverteilung der Einkommen spielte demgegenüber als Wertvorstellung in der bundesrepublikanischen Sozialpolitik eine untergeordnete Rolle, obgleich einzelnen Programmen wie der Sozialhilfe und dem Lastenausgleich redistributive Effektive nicht abzusprechen sind. Eine durchgängige egalitäre Komponente hatten die sozialpolitischen Maßnahmen nur in ihrem Bemühen, auch die am Markt unterprivilegierten oder nicht über Marktchancen verfügenden Bürger an der Lebensstandardsteigerung im Zuge des Wirtschaftswachstums teilhaben zu lassen. Die folgenden Abschnitte beschreiben dieses Bemühen des Gesetzgebers genauer anhand der Entwicklung der hier als Kernbereich des Wohlfahrtsstaates identifizierten Programme der Einkommenssicherung.

\section{(2) Kennzeichen und Hauptentwicklungsschrit- te der einzelnen Programme}

Bei Kriegsende stellten sich der deutschen Politik vor allem die Aufgaben des wirtschaftlichen Wiederaufbaus, der Wohnraumbeschaffung und der Integration der Flüchtlinge und Kriegsgeschädigten. Die Kriegsopferversorgung konnte auf den nach dem Ersten Weltkrieg gesammelten Erfahrungen mit dem Reichsversorgungsgesetz von 1920 aufbauen. Die Leistungen des inzwischen mehrfach novellierten Bundesversorgungsgesetzes von 1950 werden aus allgemeinen Steuermitteln finanziert. Die wiederholt angehobenen Leistungssätze sind seit 1970 ,,dynamisiert", d.h. der Entwicklung der Löhne und Gehälter angepaßt. Die Zahl der Leistungsempfänger, die 1950 noch über 4 Millionen lag, ist inzwischen deutlich zurückgegangen. Heute erhalten noch etwa 2 Millionen Bürger Zuwendungen. Die Aggregatausgaben beliefen sich 1978 auf rund 13 Mrd. $\mathrm{DM}^{4}$.

Im Gegensatz zur Kriegsopferversorgung war der Lastenausgleich für zivile Geschädigte des Krieges, insbesondere die etwa 10 Millionen Flücht-

4 Sofern nichts anderes vermerkt ist, stützen sich alle Zahlenangaben in diesem Abschnitt auf die im Literaturverzeichnis aufgeführten Veröffentlichungen des Bundesministeriums für Arbeit und Sozialordnung. Sie sind dort entweder direkt gegeben oder vom Autor aufgrund der dort präsentierten Zahlen neu berechnet worden. 
linge, ohne Vorbild. Zumindest auf dem Papier markierte die 1952 nach einigen vorherigen Soforthilfegesetzen begonnene Lastenausgleichsgesetzgebung eine der drastischsten Umverteilungsmaßnahmen der Geschichte mit friedlichen Mitteln. Die Leistungen wurden durch eine Vermögensabgabe in Höhe von 50 Prozent auf das 1948 auf dem Gebiet der Bundesrepublik erhaltene Vermögen finanziert. Allerdings konnte die Schuld auf vierteljährliche Zahlungen im Zeitraum von 30 Jahren verteilt werden, so daß das Verfahren umgerechnet auf eine jährliche Steuer von $1.66 \%$ des Vermögenswertes von 1948 hinauslief. Die Leistungen bestanden in Eingliederungsdarlehen und Entschädigungen sowie in Rentenzahlungen und Unterhaltshilfen, die 1974 dynamisiert wurden. Mit der 28. Novellierung wurde die Lastenausgleichsgesetzgebung 1977 formell abgeschlossen. Ihre Gesamtkosten werden sich auf ca. $140 \mathrm{Mrd}$. DM belaufen, wobei die jährlichen Zahlungen im letzten Jahrzehnt etwa 4 Mrd. DM betrugen.

Die Versuche der Regierung, das bei Kriegsende drängende Wohnungsproblem zu lösen, lassen sich in 3 Kategorien klassifizieren: Kontrollen des Wohnungsmarktes, die später einer reinen Subventionierung des Wohnungsbaus wichen, Mieterschutz und Wohngeld für niedrige Einkommensgruppen. Die bis 1960 betriebene Bewirtschaftung des Wohnungsmarktes wurde schon früh durch steuerliche Anreize zur Förderung des privaten Wohnungsbaus ergänzt. Spezielle Fördermaßnahmen kamen Bauherren zugute, die bereit waren, sich im Rahmen des sozialen Wohnungsbaus Auflagen zur Gestaltung des Mietverhältnisses und des Mietpreises zu fügen. Der Einsatz der verschiedenen Instrumente trug zu einer raschen Entschärfung des Wohnungsproblems bei. Die im Krieg verlorenen 2.3 Millionen Wohnungen waren 1954 ersetzt, und bis in die siebziger Jahre verzeichnete jedes Jahr einen Zuwachs von 500.000 oder mehr Neubauwohnungen. Heute entspricht die Gesamtzahl der Wohnungen in etwa der Zahl der Haushalte (Glatzer 1976: 513). Der Abbau der Marktkontrollen im Jahr 1960, in dessen Rahmen die Rechtsposition der Mieter erheblich geschwächt wurde, wurde von der Einführung eines Wohngeldes begleitet. Gegenwärtig beziehen etwa 7\% (1.7 Millionen) aller Haushalte diese an Einkommensgrenzen gebundene Unterstützung, für die pro Jahr insgesamt etwa $2 \mathrm{Mrd}$.
DM aufgewendet werden. Neue Mieterschutzgesetze haben seit 1971 und 1974 die Rechtsposition der Mieter wieder gestärkt.

Die klassischen Sozialversicherungssysteme sind seit ihrer Wiedereinfuihrung durch das Sozialversicherungsanpassungsgeset $z$ von 1949 in ihrer organisatorischen Struktur weitgehend unverändert geblieben ${ }^{5}$. Allerdings zeigt Tabelle 1, daß sie erheblich ausgebaut wurden.

Die am wenigsten tiefgreifenden Umstrukturierungen erfuhr die Unfallversicherung. Hier wurde der wichtigste Reformschritt 1963 unternommen, als die Leistungen an die Entwicklung der Löhne und Gehälter angepaßt wurden und das Instrumentarium zur Unfallverhütung ausgebaut wurde. Die Zahl der Betriebsunfalle, die zwischen 1950 und 1960 ständig zugenommen hatte (von 1.3 Millionen auf 2.7 Millionen), ist seither kontinuierlich gesunken und nähert sich wieder dem Niveau der frühen fünfziger Jahre (1975: 1.8 Millionen). In der Gesetzgebung der letzten Jahre gewann die Unfallprophylaxe zusätzliches Gewicht. Die Gesamtausgaben für die Unfallversicherung betrugen $19501 \mathrm{Mrd}$. DM, 19788 Mrd. DM. Damit ist die Unfallversicherung das finanziell bescheidenste der Sozialversicherungsprogramme.

Doppelt so viel - 1978 etwa 19 Mrd. DM 6 wird für die Arbeitslosenversicherung aufgebracht, den zweiten finanziell bescheidenen Zweig der Sozialversicherung. Die Gesetzgebung der Nachkriegszeit zielte primär auf eine Erweiterung der präventiven Kapazitäten der Arbeitsämter zur Erhaltung oder Schaffung von Arbeitsplätzen. Vor allem das Arbeitsförderungsgesetz von 1969 verbesserte das Instrumentarium zur vorbeugenden Bekämpfung der Arbeitslosigkeit durch Berufsbildungsprogramme und ausgedehntere Möglichkeiten der

5 Die vielleicht wichtigste Änderung brachte das Selbstverwaltungsgesetz von 1951 , das den traditionellen Verteilungsschlüssel der Arbeitnehmer- und Arbeitgebersitze in den Verwaltungsorganen zugunsten der gleichen Repräsentation in allen Programmen änderte. Vorher hatten die Arbeitnehmervertreter zwei Drittel der Sitze in der Krankenversicherung, aber keine in der Unfallversicherung.

6 Inkl. der Ausgaben für Arbeitsförderung. 
TABELLE 1 Die Bestimmungen der Sozialversicherungsgesetze in der Bundesrepublik 1949, 1969, 1978*

\begin{tabular}{|c|c|c|c|c|c|c|c|c|c|c|c|c|}
\hline \multirow[b]{2}{*}{$\begin{array}{l}\text { Ausdehnung } \\
\text { Zahl der Versich. } \\
\text { (\% d Erwerbsbev.) } \\
\text { Pflichtverusche- } \\
\text { rungsgrenze }\end{array}$} & \multicolumn{3}{|c|}{ Rentenversicherung } & \multicolumn{3}{|c|}{ Krankenversicherung } & \multicolumn{3}{|c|}{ Arbeitslosenver sicherung } & \multicolumn{3}{|c|}{ Unfallversicherung } \\
\hline & $\begin{array}{l}1949 \\
15 \mathrm{M} 10 \\
(66 \%) \\
600 . \\
(3.2 \text { mal } \\
\text { Durch- } \\
\text { schn- } \\
\text { lohn })\end{array}$ & \multicolumn{2}{|c|}{$\begin{array}{l}\text { alle Arbester } \\
\text { und Angestellten }\end{array}$} & $\begin{array}{l}1949 \\
13 \mathrm{M} 10(57 \%) \\
34 \mathrm{M} 10(72 \%) \\
375 .- \\
(2.0 \text { mal } \\
\text { Durchschn.- } \\
\text { lohn) }\end{array}$ & $\begin{array}{l}1969 \\
17 \mathrm{M} 10(63 \%) \\
54 \mathrm{M} 10(88 \%) \\
990 .- \\
(1.0 \mathrm{mal} \\
\text { Durchschn. } \\
\text { lohn) }\end{array}$ & $\begin{array}{l}1978 \\
20 \mathrm{Mo}(79 \%) \\
56 \mathrm{Mo}(92 \%) \\
\\
2.775 .- \\
(1.2 \mathrm{mal} \\
\text { Durchschn - } \\
\text { lohn) }\end{array}$ & \multicolumn{3}{|c|}{$\begin{array}{l}600 .-\quad \text { alle Arbeiter } \\
\text { (3.2 mal und Angestellten } \\
\text { Durchschn.- } \\
\text { lohn) }\end{array}$} & \multicolumn{3}{|c|}{ 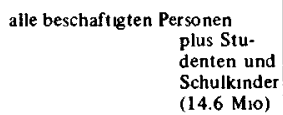 } \\
\hline \multirow[t]{2}{*}{$\begin{array}{l}\text { Lestungen } \\
\text { Absolutbetrage } \\
\text { und Leistungssat z } \\
\text { in } / \text { der durch- } \\
\text { schn. Nettolohne }\end{array}$} & \multirow{2}{*}{$\begin{array}{l}\text { Grund- } \\
\text { rente } \\
50 \text {, } \\
(27 \%) \\
\text { Durch- } \\
\text { schn. } \\
\text { rente } \\
60 . \\
(33 \%)\end{array}$} & \multirow{2}{*}{$\begin{array}{l}\text { nach } \\
45 \text { Jah- } \\
\text { ren } \\
517 .- \\
(66 \%) \\
\text { Durch- } \\
\text { schn. } \\
\text { rente } \\
353 .- \\
(40 \%)\end{array}$} & \multirow{2}{*}{$\begin{array}{l}\text { nach } \\
45 \text { Jah- } \\
\text { ren } \\
1134- \\
(72 \%) \\
\text { Durch } \\
\text { schn. } \\
\text { lente } \\
641 .- \\
(46 \%)\end{array}$} & \multirow{2}{*}{$\begin{array}{l}50 \% \text { des } \\
\text { Bruttover- } \\
\text { dienstes } \\
\text { abs. Grenze: } \\
6.25 \text { p/Tag }\end{array}$} & \multirow{2}{*}{$\begin{array}{l}\text { volle Lohn- } \\
\text { fortzahl. } \\
\text { fur } 6 \text { Wochen } \\
75 \% \text { danach } \\
\text { (b1s zum Net- } \\
\text { toverdienst) } \\
\text { Grenze: } \\
\text { 30.- p./Tag }\end{array}$} & \multirow{2}{*}{$\begin{array}{l}\text { volle Lohn- } \\
\text { fortzahl. } \\
\text { fur } 6 \text { Wochen } \\
80 \% \text { danach } \\
\text { (bis zum Net- } \\
\text { toverdienst) } \\
\text { Grenze: } \\
68 .- \text { p/Tag }\end{array}$} & \multicolumn{3}{|c|}{$\begin{array}{l}2040 \quad 114.60 \quad 247.80 \\
\text { pro Wo- pro Wo- pro Woche } \\
\text { che che } \\
\text { fur Durchschnuttsverdiener }\end{array}$} & \multirow{2}{*}{\multicolumn{3}{|c|}{ 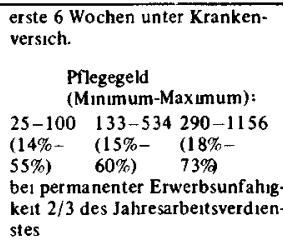 }} \\
\hline & & & & & & & $45 \%$ & $62.5 \%$ & $68 \%$ & & & \\
\hline Lesstungsdauer & - & - & - & 26 Wochen & $\begin{array}{l}78 \text { Wochen } \\
\text { Krankenhaus- } \\
\text { pflege } \\
78 \text { Wochen }\end{array}$ & $\begin{array}{l}78 \text { Wochen } \\
\text { Krankenhaus- } \\
\text { pflege } \\
\text { unbegrenzt }\end{array}$ & $\begin{array}{l}26 \text { Wo- } \\
\text { chen } \\
\text { (max.) } \\
\quad \text { plus }\end{array}$ & $\begin{array}{l}52 W_{0}- \\
\text { chen } \\
\text { (max.) } \\
\text { Arbeitslos }\end{array}$ & $\begin{array}{l}52 \text { Wo- } \\
\text { chen } \\
\text { (max.) } \\
\text { senhilfe }\end{array}$ & - & - & - \\
\hline $\begin{array}{l}\text { Bettrage als \% } \\
\text { der Brut tover- } \\
\text { dienste }\end{array}$ & $10 \%$ & $17 \%$ & $18 \%$ & (D.0\% & $\begin{array}{l}105 \% \\
\text { Initt aller Kasse }\end{array}$ & $11.4 \%$ & $4.0 \%$ & $1.3 \%$ & $3 \%$ & $\begin{array}{l}\text { Arbeltge } \\
\text { ca. } 1.5 \%\end{array}$ & $\begin{array}{l}\text { berbeitra } \\
\text { der Arbe }\end{array}$ & $\begin{array}{l}\text { In Hohe von } \\
\text { sverdienste }\end{array}$ \\
\hline $\begin{array}{l}\text { Finanzierungs- } \\
\text { quelle } \\
\text { Antesl der Versi- } \\
\text { cherten, d. Arbeit- } \\
\text { geber u.d. Staates }\end{array}$ & $\begin{array}{l}\text { Vers.: } \\
1 / 2 \\
\text { A.geb.: } \\
1 / 2 \\
\text { Staat: } \\
\text { etwa } \\
19 \% \text { d. } \\
\text { Kovten }\end{array}$ & $\begin{array}{l}1 / 2 \\
1 / 2 \\
\text { etwd } \\
15 \% \mathrm{~d} \\
\text { Kosten }\end{array}$ & $\begin{array}{l}1 / 2 \\
\text { etwa } \\
18 \% \text { d. } \\
\text { Kosten }\end{array}$ & $1 / 2$ & $\begin{array}{l}1 / 2 \\
\text { Plus Lohnfortz } \\
\text { fur } 6 \text { Wochen }\end{array}$ & hlong & $\begin{array}{l}1 / 2 \\
1 / 2 \\
\text { Staat zah } \\
\text { und Defiz }\end{array}$ & $\begin{array}{l}1 / 2 \\
1 / 2 \\
\text { it Arbeitsic }\end{array}$ & $\begin{array}{l}1 / 2 \\
\text { osenh } 11 \mathrm{fe}\end{array}$ & nus $A$ & rbestgebe & \\
\hline $\begin{array}{l}\text { Bettragsbemes- } \\
\text { sungsgrenze }\end{array}$ & $\begin{array}{l}600 \\
(3.2 \text { mal } \\
\text { Durch- } \\
\text { schnitts- } \\
\text { lohn) }\end{array}$ & $\begin{array}{l}1700 .- \\
(1.7 \mathrm{mal} \\
\text { Durch- } \\
\text { schnitts- } \\
\text { lohn) }\end{array}$ & $\begin{array}{l}3700 .- \\
(1.6 \text { mal } \\
\text { Durch- } \\
\text { schnitts- } \\
\text { lohn) }\end{array}$ & $\begin{array}{l}375 .- \\
(2.0 \mathrm{mal} \\
\text { Durch- } \\
\text { schnitts- } \\
\text { lohn) }\end{array}$ & $\begin{array}{l}990 . \\
(1.0 \mathrm{mal} \\
\text { Durch- } \\
\text { schnitts- } \\
\text { lohn) }\end{array}$ & $\begin{array}{l}2775 .- \\
(1.2 \text { mal } \\
\text { Durch- } \\
\text { schnitts- } \\
\text { lohn) }\end{array}$ & $\begin{array}{l}375 .- \\
(2.0 \mathrm{mal} \\
\text { Durch- } \\
\text { schnitts- } \\
\text { lohn) }\end{array}$ & $\begin{array}{l}1300 .- \\
\text { (1 } 7 \mathrm{mal} \\
\text { Durch- } \\
\text { schnitts- } \\
\text { lohn) }\end{array}$ & $\begin{array}{l}3700 .- \\
\text { (1.6 mal } \\
\text { Durch- } \\
\text { schnitts- } \\
\text { lohn) }\end{array}$ & - & - & - \\
\hline $\begin{array}{l}\text { Kontrollen: Lange } \\
\text { der Wartezest: }\end{array}$ & - & & - & 3 Tage & $\mathbf{0}$ & 0 & 7 Tage & $\mathbf{0}$ & 0 & 3 Tage & 0 & 0 \\
\hline
\end{tabular}

* 1949: Bestımmungen des ,Sozıalversicherungsanpassungsgesetzes" (Unfallvers.: Gesetz vom 10.8.1949). 1969. Gultige Bestımmungen vor der sozıallıberalen Kou.. lition.

1978: Geltende Best Immungen.

Alle genannten Emkommensgrenzen sind gesetzlıch verordnet die Leistungssatze sind gesetzlich festgelegt in der Krankenversicherung und in der Arbeitslosenvers. selt 1969. Alle anderen Leist ungssatze sind vom Autor berechnet, basierend auf Angaben im Sozialbericht 1978: 316 (Netto) und 319 (Brutto) Einkommen fur 1949 wurden durch Interpolation der Angaben fur 1948 und 1950 in Bundesministerium fur Arbeit 1970: 67 berechnet. Die Zahlen fur die Rentenvers. beziehen sich auf die Arbettervers., die zweiten Vers.-zahien fur die Krankenvers. auf die gesamte versicherte Bevolkerung, inkl. Familıenmitglieder (\% der Bevolk.). Die Anteile unter "Funanzicrungsquelle" zeigen, wie der genannte Beitragssatz auf Arbeitnehmer und Arbeitgeber verteilt ist: die Staatsanteile beziehen sich auf den Anteil der Aggregatkosten der Programme.

\section{Arbeitsvermittlung? ${ }^{7}$ Seit der Rezession von} 1973/74 erhalten jährlich etwa 800.000 Personen, das sind etwa 80\% aller Arbeitslosen, Leistungen in Form von Arbeitslosengeld oder -hilfe.

7 Angesichts der gegenwärtig hohen Arbeitslosenzahlen mag man mit Recht Zweifel an der Angemessenheit dieses präventiven Instrumentariums anmelden. Nach Angaben von Josef Stingl (1977: 358), dem Präsidenten des Bundesarbeitsamtes, wären die gegenwärtigen Arbeitslosenzahlen allerdings noch um etwa ein Drittel höher, wenn die neuen Instrumente nicht zur Verfügung gestanden hatten.
Sehr viel mehr Geld als die Unfall- und Arbeitslosenversicherung beansprucht die Krankenversicherung, deren Ausgaben nur noch von der Rentenversicherung übertroffen werden. Die traditionelle deutsche Gesundheitspolitik wurde in der Bundesrepublik 1955 durch das Krankenkassen- und das Kassenarztgesetz restauriert. Demnach obliegt die Verantwortung für die Sicherstellung der gesundheitlichen Versorgung selbstverwalteten ärztlichen Organisationen, die in Verhandlungen mit den Repräsentanten der Krankenkassen die jährliche Gesamtvergütung vereinbaren, die dann durch die kassenärztlichen Vereinigungen unter den Ärzten nach einem 
Punktsystem verteilt wird ${ }^{8}$. Die Geldleistungen im Krankheitsfall wurden 1957 und in den folgenden Wahljahren schrittweise angehoben, bis 1969 auch für Arbeiter die für Angestellte schon früher bestehende volle Lohnfortzahlung bis zu 6 Wochen eingefuihrt wurde. Diverse Leistungserweiterungen im Bereich der medizinischen Versorgung führten in Verbindung mit dem relativ konstanten Krankenstand der versicherten Bevölkerung' und der Technisierung der Medizin zu einer Kostenexplosion im Gesundheitswesen. Die Ausgaben der Kassen steigen seit dem Ende der sechziger Jahre mit jährlichen Zuwachsraten über 10 Prozent (Holler 1977: 313), so daß sich der Anteil der Gesundheitsausgaben am Sozialprodukt zwischen 1960 und 1970 verdoppelte, während die Beitragsbelastung, trotz der Übernahme der Lohnfortzahlung durch die Arbeitgeber, weiter stieg. Im Aggregat betrugen die Ausgaben 1978 (inkl. Lohnfortzahlung) rd. 100 Mrd. DM oder 7\% des Sozialprodukts. Die Gesetzgebung steht seit 1975 im Zeichen des Bemühens, die Kostenentwicklung zu bremsen. Während das neue Kassenarztgesetz von 1976 die Verhandlungsmacht der Kassen stärkte, fuhrte das Kostendämpfungsgesetz von 1977 striktere Leistungskontrollen ein und begründete eine konzertierte Aktion im Gesundheitswesen zur planvolleren Steuerung der Ausgaben.

Auch die Rentenversicherung sah sich mit einer stürmischen Entwicklung der Ausgaben konfrontiert. Die demographischen Umschichtungen ließen einen Rentenberg heranwachsen, dessen Höhe von 4.5 Millionen Renten im Jahr 1950 auf 11.6 Millionen 1976 stieg (inkl. Invalidenund Hinterbliebenenrenten). Zwei wichtige Reformschritte markieren die Nachkriegsentwicklung der Rentenversicherung: die Einführung der dynamischen Rente 1957, die mit der Abschaffung der aus allgemeinen Steuermitteln finanzierten Grundrente verbunden war, und die Einführung der flexiblen Altersgrenze 1972. Im Kontext der Scherenentwicklung von steigenden

8 Jede ärztliche Leistung hat einen bestimmten Punktwert. Der monetäre Wert jedes Punktes bestimmt sich durch die jährliche Höhe der Gesamt vergütung und die jährliche Gesamtpunktzahl, die sich durch die Summe der erbrachten ärztlichen Leistungen ergibt.

9 Im Durchschnitt sind etwa 5-6\% der Versicherten zu einem gegebenen Zeitpunkt erkrankt (Helberger 1976: 580).
Rentnerzahlen und sinkender Zahl der Beitragszahler zogen die diversen Leistungsverbesserungen der Reform von 1972 wachsende Defizite nach sich, die trotz steigender Beitragssätze nicht voll aufgefangen werden konnten. Sanierungsgesetze der Jahre 1977 und 1978 setzten die quasi-automatische Steigerung der Renten in Anlehnung an die Bruttogehälter der Versicherten bis 1981 aus, was, zusammen mit anderen Konsolidierungsmaßnahmen, zu einem deutlich gebremsten Anstieg der Leistungen führte. Seither betrug der jährliche Zuwachs der Renten noch 4 bis 4.5 Prozent. Die weiter steigenden Gesamtausgaben streiften 1978 die Marke von 130 Mrd. DM, was gegenüber 1957 einem fast zehnfachen (nominalen) Zuwachs entspricht.

Der Ausbau des Sozialversicherungssystems konnte nicht verhindern, daß auch die Ausgaben für die Sozialhilfe wuchsen. Ein formeller Rechtsanspruch auf Leistungen der Sozialhilfe besteht seit einer Entscheidung des Bundesverwaltungsgerichts aus dem Jahr 1954 und ist im Bundessozialhilfegesetz des Jahres 1961 unterstrichen. Nach diversen Anhebungen wurden die Sozialhilfesätze 1974 dynamisiert. Während die Zahl der Sozialhilfeempfänger im Jahrzehnt 1950 bis 1960 rückläufig war (von 1.6 auf 1.1 Millionen), zeigt sie in den letzten Jahren steigende Tendenz. 1974 bezogen 2.2 Millionen Personen Leistungen. Die Regelsätze der Hilfe zum Lebensunterhalt (ohne die gesondert getragenen Wohnkosten) entsprachen 1977 im Bundesdurchschnitt 19\% der Nettodurchschnittsverdienste der beschäftigten Arbeitnehmer (1957: $17 \%)^{10}$. Die Gesamtausgaben überquerten 1977 erstmals die 10 Milliarden-Marke und belaufen sich heute auf rd. 15 Milliarden.

Während Deutschland auf den meisten sozialpolitischen Gebieten im internationalen Vergleich als Pionier erscheint, wurde das Kindergeld erst vergleichsweise spät eingeführt. Nach der Abschaffung der unter nationalsozialistischer Herrschaft (1935) eingeführten Zahlungen an kinderreiche Familien ab dem füften Kind stützte sich die bundesrepublikanische Familienförderung zunächst auf indirekte Leistungen durch steuerrechtliche Kinderfreibeträge. Dieses, die

10 Für die diesen Berechnungen des Autors zugrundeliegenden Lohnstatistiken vgl. die Anmerkungen zu Tabelle 1. 
höheren Einkommensgruppen wegen der progressiven Steuersätze begünstigende Verfahren wurde erstmals 1954 durch direkte Zahlungen für Familien mit drei und mehr Kindern zu Lasten der Arbeitgeber ergänzt. 1961 wurde zusätzlich ein aus allgemeinen Steuermitteln des Bundes finanziertes Kindergeld für das zweite Kind eingefuihrt. Mit dem Bundeskindergeldgesetz von 1964 übernahm der Bund dann die Kosten des Kindergeldes insgesamt. Erstmals wurden dabei die Zahlungen an Einkommensgrenzen gebunden. Das zweigleisige System von steuerrechtlichen Kinderfreibeträgen und direkten Leistungen wurde erst 1975 aufgegeben, als ein allgemeines Kindergeld $a b$ dem ersten Kind für alle Familien, unabhängig vom Einkommen, eingeführt wurde. 1978 betrug das Kindergeld 50 DM für das erste, $80 \mathrm{DM}$ für das zweite und $150 \mathrm{DM}$ für jedes weitere Kind. Im Aggregat addierten sich diese Leistungen im gleichen Jahr auf 15 Mrd. DM.

Die Ausbildungsförderung blieb verfassungsrechtlich lange den Ländern vorbehalten. Eine bundeseinheitliche Regelung brachte erstmals das kurz vor den Wahlen 1965 eingeführte „Pennälergehalt", das als Ausbildungszulage im Rahmen des Kindergelds konzipiert war, aber bereits 1967 den öffentlichen Sparmaßnahmen zum Opfer fiel. Nach dem Übergang der Gesetzgebungskompetenz an den Bund wurden mit dem Bundesausbildungsförderungsgesetz von 1969 erstmals reguläre staatliche Beihilfen zur Finanzierung der Schul- und Hochschulbildung eingeführt. In den Folgejahren wurden die Leistungen mehrfach erweitert. 1976 bezogen etwa 24 Prozent der Schüler der Sekundarstufe II und 38 Prozent der Studenten Beihilfen (1970: 30 und 45 Prozent). Die Leistungen sind an Einkommensgrenzen gebunden und bis zur Grenze degressiv gestaffelt. Im Durchschnitt beliefen sie sich 1976 auf monatlich $245 \mathrm{DM}$ für Schüler und $425 \mathrm{DM}$ für Studenten. Die Ausgaben, die zu zwei Dritteln aus allgemeinen Steuermitteln des Bundes, zu einem Drittel von den Ländern getragen werden, bezifferten sich 1978 auf etwas mehr als 3 Mrd. DM.

An Plänen zur Ergänzung der sozialen Transferzahlungen durch eine gesetzlich verankerte Vermögensbildung in Arbeitnehmerhand bestand in der Bundesrepublik seit den fünfziger Jahren kein Mangel, aber die Realisierung blieb bis heute auf bruchstückhafte Teilversuche beschränkt.
1959 wurde die ursprüngliche Förderung der privaten Vermögensbildung durch steuerliche Vergünstigungen durch die Einführung von Sparprämien ergänzt. Sowohl die Höhe der Prämien wie die der prämienbegünstigten Sparbeträge wurde in der Folgezeit wiederholt angehoben. Das ursprünglich allen Gruppen offenstehende Prämiensparen wurde 1975 an Einkommensgrenzen gebunden. Vermögenswirksame Leistungen der Arbeitgeber fanden erstmals durch das Vermögensbildungsgesetz von 1961 (312-DM-Gesetz) staatliche Förderung. Das 3. Vermögensbildungsgesetz von 1970 verdoppelte den förderungsfähigen Betrag auf 624 DM und ersetzte die bisherige indirekte steuerrechtliche Förderung durch die direkte Zahlung einer Sparzulage, die 1974 an Einkommensgrenzen gebunden wurde. Heute sparen mehr als 16 Millionen Arbeitnehmer im Rahmen des Vermögensbildungsgesetzes (Ruf 1977: 428). Weitergehende Pläne zur Vermögensbildung in Arbeitnehmerhand sind von der Bundesregierung im vergangenen März, entgegen den Ankündigungen der Regierungserklärung zu Beginn der Legislaturperiode, auf Eis gelegt worden.

\section{(3) Phasen und Trends der sozialpolitischen Entwicklung}

Betrachtet man die Entwicklung der geschilderten sozialpolitischen Programme in übergreifender Perspektive, so lassen sich relativ deutlich fünf Phasen der Entwicklung des Wohlfahrtsstaats in der Bundesrepublik unterscheiden: (1) eine Phase des institutionellen Aufbaus von 1949 bis 1955; (2) eine Phase der Ausdehnung, verbunden mit dem Scheitern grundlegender Neuordnungspläne, etwa von 1955 bis 1966; (3) eine Phase finanzieller Sanierung, begleitet von einer Akzentverlagerung von sozialem Konsum zu sozialer Investition, 1966 bis 1969; (4) eine Phase der Leistungserweiterung, 1969 bis 1974; (5) eine Phase der finanziellen Konsolidierung mit gebremstem Wachstum und teilweisen Leistungskurzungen, 1975 bis 1980 (+ ?).

Die Regierungserklärungen zu Beginn der Legislaturperioden des Bundestages spiegeln die genannten Phasen in recht ausgeprägter Form wider. Unter der ersten Kanzlerschaft Konrad Adenauers 1949 bis 1953 figurierte die Sozialpolitik explizit als Magd der wirtschaftlichen 
Entwicklung. Als ,beste Sozialpolitik“ galt ,eine gesunde Wirtschaftspolitik" (von Beyme 1979: 64). Wachstumsanreize und die Schaffung von Aufstiegschancen standen im Zentrum der politischen Bemühungen. Die private Kapitalakkumulation wurde mit allen erdenklichen Mitteln gefördert. Innerhalb der Sozialpolitik hatten die Entschädigung der Kriegsfolgelasten und die Integration der Flüchtlinge Priorität. Die traditionellen Institutionen der Sozialpolitik wurden durch eine Reihe von Aufbaugesetzen restauriert, aber darüber hinaus durch eine unabhängige Sozialgerichtsbarkeit ergänzt. Die Leistungsgesetze zielten meist darauf ab, das ursprüngliche Niveau der Leistungssätze durch Anpassung an die wirtschaftliche Entwicklung zu erhalten ${ }^{11}$.

In seiner Regierungserklärung zur Eröffnung der 2. Legislaturperiode versprach Adenauer, die Sozialleistungsempfänger auch weiterhin am wirtschaftlichen Wachstum teilhaben zu lassen, kündigte gleichzeitig aber die Vorbereitung einer grundlegenden Sozialreform an (von Beyme 1979: 81). 1955 wurde zu diesem Zweck im Bundesarbeitsministerium ein Generalsekretariat für die Sozialreform gebildet, das eine Neuordnung der sozialen Leistungen nach stärker finalen statt kausalen Kriterien und damit eine verbesserte Koordination der Leistungssysteme vorbereiten sollte. Von diesen ambitiösen Plänen konnte außer der Rentenreform von 1957 nur wenig in die Praxis umgesetzt werden. Vor allem der Versuch, die Krankenversicherung durch eine teilweise Kostenbeteiligung der Versicherten umzuordnen, traf auf erbitterten Widerstand und wurde nach zehnjährigen Auseinandersetzungen $1965 \mathrm{zu}$ den Akten gelegt (s. Richter/ Müller 1967). Der Verzicht auf grundlegende Strukturreformen wurde mit diversen Ausdehnungen und Leistungsverbesserungen der traditionellen Programme verzuckert.

Weiterer Expansion setzte erstmals die Rezession der Jahre 1966/67 ein Ende. In der Regierungs-

11 Zöllner (1963: 22 f.) hat in diesem Zusammenhang die nützliche Unterscheidung von "adaptiven" und ,induktiven" Leistungsgesetzen getroffen. Während adaptive Regelungen lediglich das bisherige Niveau durch Anpassung an ökonomische Veränderungen sichern, bringen induktive Gesetze reale Leistungssteigerungen. Eine auf dieser Unterscheidung aufbauende Typologie gesetzgeberischer Maßnahmen im Bereich der Sozialpolitik findet sich in Alber (1979: 176). erklärung der Großen Koalition kündigte Kurt Georg Kiesinger eine Sanierung der Sozialausgaben an, die in Einklang mit den Grundsätzen einer gesunden Finanzpolitik gebracht werden sollten. Das unkontrollierte Wachstum der Ausgaben für den sozialen Konsum sollte zugunsten der Förderung sozialer Investitionen in den Hintergrund treten (s. von Beyme 1979: 235-36). Während einige Leistungen wie das Pennälergehalt dem Rotstift anheimfielen, andere gekürzt oder - durch Hebung der Beitragssätze - verteuert wurden, akzentuierten neue Gesetze wie vor allem das Arbeits- und das Ausbildungsförderungsgesetz von 1969 den Gedanken einer präventiven Sozialpolitik. Erstmals kam der Bildungspolitik in diesem Rahmen eine gewisse Priorität zu.

Die Ansätze zu einer aktiven, sozial gestaltenden Politik des Staates erhielten zusätzlichen Auftrieb, als die sozialliberale Koalition die Regierung übernahm und der erneute wirtschaftliche Aufschwung die Staatskassen füllte. Während die Leistungen für den sozialen Konsum, insbesondere durch die Rentenreform von 1972, beträchtlich erweitert wurden, gewannen gleichzeitig präventive Maßnahmen an Gewicht, so durch gesundheitliche Vorsorgeuntersuchungen und ein umfangreiches Programm zur Humanisierung der Arbeit. Der Aufbruch zu neuen sozialpolitischen Horizonten erlitt einen ernsthaften Rückschlag, als die Rezession nach der ölkrise mit beispiellosen Kostensteigerungen im Renten- und Gesundheitssektor zusammentraf. In seiner Regierungserklärung zur Eröffnung der 8. Legislaturperiode sah sich Bundeskanzler Schmidt zu der Erinnerung veranlaßt, daß die Sozialpolitik jährlich nur die Summen ausgeben könne, die die Volkswirtschaft erarbeitet (von Beyme 1979: 342). Die vergangenen Jahre standen dementsprechend im Zeichen von Sanierungsversuchen, wobei die oben beschriebenen Eingriffe in die Renten- und Krankenversicherung von verschiedenen subtileren und weniger sichtbaren Sparmaßnahmen - etwa durch die Änderung der Auslegungskriterien für ,zumutbare“ Stellenangebote in der Arbeitslosenversicherung begleitet waren.

Ob diese Sparmaßnahmen ein Ende des Wachstums des Wohlfahrtsstaats signalisieren oder lediglich das Tempo des Wachstums verlangsamen, bleibt abzuwarten. In der Vergangenheit 
waren Leistungskürzungen stets von vorübergehendem Charakter und ohne nennenswerten Einfluß auf den historischen Trend zur Expansion der Sozialleistungen, der sich sowohl quantitativ anhand der Ausgaben wie qualitativ anhand der gesetzlichen Veränderungen illustrieren läßt. Auf dem Gebiet der Gesetzgebung hat der Wohlfahrtsstaat ständig seine Funktionen erweitert. Indem er sich nicht mehr nur für die Bedürftigen, sondern für die gesamte Bevölkerung als verantwortlich erklärt, ist er kontinuierlich von unten nach oben durch die Sozialstruktur vorgerückt - wobei er in Deutschland, im Gegensatz zu anderen Ländern, allerdings meist vor den Selbständigen Halt gemacht hat. Ständig hat der Wohlfahrtsstaat zusätzliche Risiken abgedeckt und damit in zunehmenden Maße eine Gesamtverantwortung für die Verteilung der Lebenschancen übernommen - ein Trend, der sich an der zunehmenden Ergänzung der sozialen Transferzahlungen durch soziale Dienste und öffentliche Guter im Zeichen einer titativ anhand der gesetzlichen Veränderungen illustrieren läßt. Auf dem Gebiet der Gesetzgebung hat der Wohlfahrtsstaat ständig seine Funktionen erweitert. Indem er sich nicht mehr nur für die Bedürftigen, sondern für die gesamte Bevölkerung als verantwortlich erklärt, ist er kontinuierlich von unten nach oben durch die Sozialstruktur vorgerückt - wobei er in Deutschland, im Gegensatz zu anderen Ländern, allerdings meist vor den Selbständigen Halt gemacht hat. Ständig hat der Wohlfahrtsstaat zusätzliche Risiken abgedeckt und damit in zunehmendem Maße eine Gesamtverantwortung für die Verteilung der Lebenschancen übernommen - ein Trend, der sich an der zunehmenden Ergänzung der sozialen Transferzahlungen durch soziale Dienste und öffentliche Güter im Zeichen einer präventiven Sozialpolitik ablesen läßt. Gleichzeitig mit der Übernahme neuer Funktionen wurde die Erfüllung der traditionellen Aufgaben verbessert, insbesondere durch den Ausbau der Leistungen der Sozialversicherung (vgl. Tabelle 1).

In quantitativen Begriffen läßt sich das Wachstum am besten durch den steigenden Anteil der Sozialleistungen am Sozialprodukt illustrieren. Die Graphik auf der folgenden Seite zeigt dazu die Entwicklung der Sozialleistungsquote, definiert als Anteil der Sozialausgaben am Bruttoinlandprodukt, gemäß der Abgrenzung des In-

GRAPHIK 1 Das Wachstum der Sozialausgaben in der Bundesrepublik

Legende:

Sozialleistungsquote (\% BIP, I.L.O. Definition

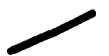

$1950-1978,1970$ bis 1978 auch Abgrenzung des Bundesarbeitsministeriums)

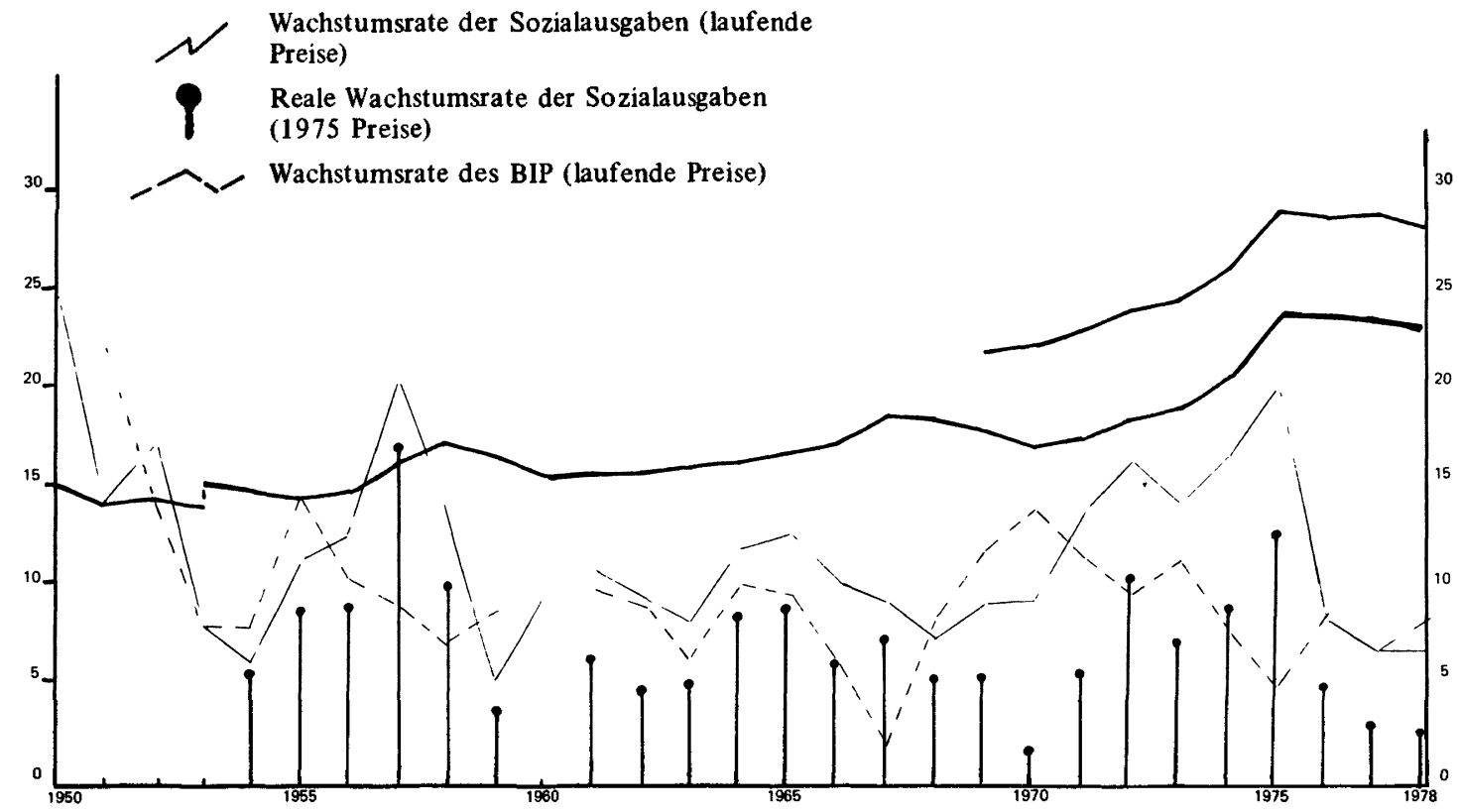


ternationalen Arbeitsamtes (ab 1950) und des Bundesarbeitsministeriums (ab 1970). Um den Kontext und das Tempo des Wandels zu illustrieren, zeigt sie darüber hinaus die nominalen und realen Wachstumsraten der Sozialleistungen sowie die nominalen Zuwachsraten des Sozialprodukts.

\section{Determinanten des Wachstums des Wohl- fahrtsstaates}

Die Frage nach den Grundlagen der historischen Ausdehnung sozialstaatlicher Aktivitäten ist lange Zeit nicht als makrosoziologische Problemstellung thematisiert worden. Erst die letzten Jahre sahen ein regeres sozialwissenschaftliches Interesse an der Sozialpolitik, das in ersten empirischen Analysen und theoretischen Arbeiten Niederschlag fand (s. zusammenfassend Alber 1979). Nach einem der anspruchsvollsten theoretischen Erklärungsversuche (Janowitz 1976) sind wachsende Sozialausgaben im wesentlichen der Ausdruck einer sinkenden Autorität demokratischer Regierungen. Im einzelnen führt Janowitz die Tendenz zu ständigen Ausgabensteigerungen auf drei miteinander zusammenhängende Entwicklungen zurück: (1) wachsende sozialpolitische Ansprüche infolge soziokultureller Wandlungen, welche individuelle Aspirationen von begrenzenden Gruppenkontrollen zunehmend freisetzen und eine hedonistische Konsumentenhaltung begünstigen; (2) die ,Demokratisierung politischer Gerechtigkeitsforderungen", in deren Rahmen die aus der Ungleichheit der Marktpositionen entspringenden Gleichheitsforderungen durch Forderungen nach einer Ausdehnung der Beteiligung am staatlichen System der Transferleistungen ergänzt werden; (3) die Schwächung demokratischer Regierungen infolge sinkender parlamentarischer Mehrheiten, die Janowitz auf die wachsende Komplexität der sozialstrukturellen Grundlagen parteipolitischer Präferenzen zurückführt, die nach seiner Einschätzung ihrerseits ein Produkt der zunehmenden Fusion von Marktund Transfereinkommen ist. Das Zusammenspiel dieser Faktoren führt zu einer, ,wachsenden Neigung, mehr zu konsumieren als produziert wurde" (1976: 45, dt. vom Verf.) und zur Ausdehnung der Sozialleistungen in Unabhängigkeit von den vorhandenen ökonomischen Ressourcen. Diese theoretisch recht ausgearbeitete Untergangsvorstellung kann hier zwar als Ganzes nicht empirisch getestet werden, aber zwei Fragen lassen sich doch genauer analysieren: (1) Hat sich das Tempo der Sozialausgabensteigerung im Zuge sinkender Regierungsmehrheiten in den letzten Jahren beschleunigt, wie es die Theorie nahelegt? (2) Gibt es Anzeichen dafür, daß das Wachstum tatsächlich zunehmend losgelöst von der Wirtschaftsentwicklung erfolgte?

Ein erster Blick auf die Graphik 1 scheint Janowitz' Mutmaßungen zu bestätigen: Die Sozialleistungsquote (nach der I.L.O. Definition), die 1950 noch bei 15 Prozent (des Bruttoinlandprodukts) lag, stieg in den siebziger Jahren steil nach oben und näherte sich der 25 ProzentMarke. Mindestens zwei Ubberlegungen stehen einer eindeutigen Interpretation dieser Entwicklung jedoch im Wege. Erstens war das Wachstum der Quote nach 1975, also in der Zeit, die die schwächste Regierungsmehrheit in der Geschichte der Bundesrepublik erlebte, leicht rückläufig $^{12}$. Zweitens hängt die Sozialleistungsquote gemäß ihrer Definition ebenso vom Sozialprodukt wie von den Sozialausgaben ab. Geht das Nationaleinkommen in Phasen der Rezession zurück, so muß die Sozialleistungsquote - ceteris paribus - steigen.

Gültigere Schlußfolgerungen sollten sich daher auf das absolute Wachstum der Sozialausgaben zu konstanten Preisen stützen. Das Tempo des realen Wachstums (in Preisen von 1975) hat sich über die Zeit nicht beschleunigt, sondern sogar leicht verlangsamt. Dies belegt zum einen die negative Trendlinie für die Nachkriegsperiode (ab 1954, $\mathrm{b}=-.14, \mathrm{r}=-.29$ ), zum anderen die Betrachtung des durchschnittlichen jährlichen Wachstums. Lagen die jährlichen Zuwachsraten in den fünfziger Jahren noch bei durchschnittlich 8.9 Prozent, so sanken sie in den sechziger Jahren auf 6.2, in den siebziger Jahren (bis 1978) auf 6.1 Prozent (vgl. die Anhangtabelle

12 Obwohl die CDU bei den Wahlen von 1957 die absolute Mehrheit gewann, wurde die Bundesrepublik stets von Kolaitionskabinetten regiert. Der Prozentsatz der von den Regierungskoalitionen beanspruchten Parlamentssitze berechnet sich nach den Wahlstatistiken in Raschke (1978) und Mackie/Rose (1974) sowie den Angaben über die Koalitionsparteien in Grosser (1970) und Kaack (1971) wie folgt: 1949: 51.7 ; 1953: 68.6; 1957: 57.7; 1961: 61.9; 1965: $59.3 ; 1966-69$ : $94.0 ; 1969$ : 51.2 : 1972 : $54.7 ; 1976: 51.0$. 
3). Unter den CDU-gefuhrten Koalitionsregierungen mit relativ üppigen Mehrheiten (bis 1969) wuchsen die Realausgaben mit einem jährlichen Tempo von $7.3 \%$ dabei schneller als unter den von der SPD angeführten Regierungen mit schwacher Mehrheit $(6.1 \%, 6.9 \%$ im Durchschnitt für den gesamten Zeitraum).

Selbst die Betrachtung der realen Ausgabensteigerungen hat allerdings bezuiglich der theoretischen Interpretation ihre Tücken. Einerseits mag die weitgehende Konstanz der Höhe der jährlichen Zuwachsraten trotz der unterschiedlichen Ausgangslagen bei ständig steigenden Ausgabenniveaus im Sinne von Janowitz als bemerkenswert erscheinen. Andererseits mußte die steigende Zahl der Leistungsberechtigten - vor allem infolge des demographischen Wandels, der den Anteil der Bevölkerung über 65 Jahren zwischen 1950 und 1978 von 9 auf 15 Prozent anwachsen ließ - auch unabhängig von gesetzgeberischen Leistungserweiterungen zu steigenden Ausgaben führen. Auch die vermutlich überproportionale Inflationsrate im Gesundheitswesen trug zur Ausgabensteigerung bei. Zwar hat die Beschreibung der Programme gezeigt, daß es auch zahlreiche legislative Leistungsverbesserungen gab (vgl. Tabelle 1), aber um abschätzen zu können, welcher Anteil der Ausgabensteigerungen gesetzgeberischen Aktivitäten in Reaktion auf politische Forderungen zugeordnet werden kann, müßten sehr viel feinere Indikatoren herangezogen werden ${ }^{13}$. Auf der Basis der groben Aggregatdaten muß man im Moment zu der Schlußfolgerung kommen, daß sich überzeugende Belege für eine galoppierende Entwicklung der Sozialausgaben als Folge steigender Konsumansprüche der Bevölkerung nicht finden lassen. Offensichtlich ist das Wachstum der Sozialleistungen ein komplexer Prozeß, der von einer größeren Vielfalt von Faktoren gesteuert wird, als es Janowitz' allgemeine Hypothesen nahelegen.

Wie steht es aber mit der Beziehung zwischen dem wirtschaftlichen Wachstum und der Ausdehnung der Sozialleistungen? Gab es hier einst eine starke Ubereinstimmung, die unter dem Einfluß schwacher Regierungen gelöst wurde? Für die Nachkriegszeit insgesamt zeigt die Korrelationsanalyse eine nur schwache Beziehung

13 So wären z.B. die Rentenausgaben pro Kopf der Bevölkerung über $65 \mathrm{zu}$ analysieren. zwischen dem Wirtschaftswachstum und dem Wachstum der Sozialausgaben $(\mathrm{r}=.18)^{14}$. Tatsächlich standen beide Veränderungsraten aber unter der von der CDU geführten Regierungen mit großen parlamentarischen Mehrheiten in deutlich stärkerem Einklang als in der Regie: rungszeit der sozialliberalen Koalition, für die sich sogar eine negative Assoziation ergibt $(\mathrm{r}=$ .37 bis $1969, \mathrm{r}=-.24$ für die Zeit seit 1970). Zwar stuitzt das Janowitz' Thesen über die Spendierfreudigkeit schwacher Regierungen, aber auch hier ist bei der Interpretation Vorsicht geboten. Zum einen erreichte der Rentenberg in den siebziger Jahren seine Spitze, so daß 9.8. Millionen Renten im Jahr 19701976 schon 11.6 Millionen Renten gegenüberstanden. 100.000 zusätzliche Rentner bedeuten für die Rentenversicherung heute jährliche Mehrausgaben von etwa einer Milliarde DM (Bundesministerium für Arbeit 1978: 19). Zum anderen waren die meisten Jahre der sozialliberalen Koalition von der Rezession gezeichnet, so daß die Kombination von steigenden Leistungsempfängerzahlen und sinkendem Wirtschaftswachstum selbst dann zu einer Negativbeziehung führen mußte, wenn der Gesetzgeber die Sozialleistungen unverändert ließ. Zwar standen die ersten Jahre der SPD/FDP-Regierung tatsächlich im Zeichen gesetzlicher Leistungserweiterungen, aber seit 1975 hat - wie oben kurz geschildert wurde - das Bemühen um die Kostendämpfung in der Sozialpolitik Priorität. Die Tatsache, daß mit Herbert Ehrenberg 1976 erstmals ein Ökonom an die Spitze des Bundesarbeitsministeriums trat, spiegelt dieses Bemühen wider und zeigt, daß auch (oder gerade?) Regierungen mit schwachen Mehrheiten bei angespannter Haushaltslage der finanziellen Sanierung Vorrang vor sozialpolitischer Expansion geben können.

14 Die Korrelationskoeffizienten beziehen sich auf jährliche Wachstumsraten der Ausgaben zu laufenden Preisen. Da beide Variablen der Inflation unterlagen, erschien eine Transformation in konstante Preise überflüssig. Wenn das Wirtschaftswachstum mit den Sozialausgaben im folgenden Jahr korreliert wird (lag 1 - Korrelation), erhöht sich der Koeffizient auf $r=.43(r=.22$ für lag 2). Theoretisch erscheint mir die Annahme sinnvoll, daß parlamentarische Ausgabeentscheidungen auf der Basis der für das laufende Jahr erwarteten Einnahmen getroffen werden, was gegen lag-Korrelationen spricht. Diese wie die meisten folgenden Analysen klammern das Jahr 1960 wegen des Bruchs in den statistischen Definitionen von den Berechnungen aus. 
Empirische Befunde mit klarerer Aussagekraft für die Hypothesen von Janowitz lassen sich vielleicht erhalten, wenn man die Ausgabenentwicklung in Wahljahren mit der in Nicht-Wahljahren vergleicht. Da kaum ein Grund dafür spricht, daß sich die Zahl der Leistungsempfänger innerhalb eines Jahres sprunghaft veränder ${ }^{15}$, würde die Tatsache einer überproportionalen Ausgabensteigerung in Wahljahren ein starkes Indiz für die These der Abhängigkeit demokratischer Politiker von den Konsumforderungen ihrer Stimmbürger darstellen. Die schwache Beziehung zwischen Wirtschaftsentwicklung und Sozialleistungen ist möglicherweise durch den Einfluß der Wahljahre zu erklären, in denen die Politiker vielleicht besonders zur Verteilung von Wahlgeschenken, unabhängig von der Haushaltslage, neigen. Die Tabelle 2 zeigt, daß die Sozialausgaben tatsächlich in etwas stärkerer Übereinstimmung mit der wirtschaftlichen Entwicklung wachsen, wenn der störende Effekt der Wahljahre beseitigt wird $(r=.22$ gegenuiber $r=.18)$. Interessanter ist jedoch das Ergebnis, daß sich der Einfluß von Wahljahren für die verschiedenen Regierungsperioden in sehr unterschiedlicher Weise bemerkbar macht. In der Regierungszeit der CDU stand das Wachstum der Sozialausgaben in Nicht-Wahljahren in recht deutlicher Beziehung zum Ertrag der Volkswirtschaft $(\mathrm{r}=.52)$, verlor diesen Bezug aber gänzlich in Wahljahren $(\mathrm{r}=$ -.17 ). In der Regierungszeit der sozialliberalen Koalition wuchsen die Sozialleistungen dagegen in Nicht-Wahljahren in stärkerer Loslösung vom Wachstum des Sozialprodukts als in der gesamten Periode einschließlich der Wahljahre $(\mathrm{r}=-.31$ gegenüber $\mathrm{r}=-.24)^{16}$.

15 Allein die Arbeitslosenzahlen sind größeren jährlichen Schwankungen unterworfen. Da die Ausgaben für die Arbeitslosenversicherung jedoch selten mehr als 5 Prozent der Gesamtausgaben für die soziale Sicherheit ausmachen, fallen diese Schwankungen insgesamt nicht sehr ins Gewicht. Im übrigen zeigt die Anhangtabelle 2, daß die Zahl der Arbeitslosen in Wahljahren gewöhnlich gesunken ist.

$16 \mathrm{Da}$ in der Regierungszeit der sozialliberalen Koalition bisher erst zwei Wahlen stattfanden, ist nur der Vergleich zwischen allen Jahren insgesamt und den Nicht-Wahljahren möglich. Da alle bundesrepublikanischen Wahlen gegen Jahresende im Herbst stattfanden, ist die implizite Annahme dieser Analysen, da $B$ Ausgabesteigerungen auf Aktivitäten des Gesetzgebers vor den Wahlen zurückzuführen sind, wohl gerechtfertigt.
TABELLE 2 Der Zusammenhang zwischen Wachstumsraten des Wirtschaftsproduktes und der Sozialausgaben in Wahljahren und Nicht-Wahljahren*

\begin{tabular}{lccc}
\hline & Wahljahre & $\begin{array}{l}\text { Nicht- } \\
\text { Wahljahre }\end{array}$ & $\begin{array}{c}\text { Sämtliche } \\
\text { Jahre }\end{array}$ \\
\hline $\begin{array}{l}\text { Gesamter } \\
\begin{array}{l}\text { Zeitraum } \\
(1951-1978)\end{array}\end{array}$ & -.02 & $.22(.15)$ & $.18(.11)$ \\
$\begin{array}{l}\text { CDU geführte } \\
\text { Regierungen } \\
(1951-1969)\end{array}$ & -.17 & $.52(.41)$ & $.37(.27)$ \\
$\begin{array}{l}\text { SPD/FDP } \\
\text { Koalition } \\
(1970-1978)\end{array}$ & $\begin{array}{l}\text { (nur Jahre) } \\
\text { 2 }\end{array}$ & -.31 & -.24 \\
\hline
\end{tabular}

* Exkl. 1960 (in Klammern: inkl. 1960).

Bevor dieses Ergebnis als Hinweis auf eine besondere Neigung christdemokratischer Politiker zur Vergabe von Wahlgeschenken interpretiert wird, muß untersucht werden, ob der gelockerte Zusammenhang zwischen Sozialausgaben und Wirtschaftsentwicklung in Wahljahren tatsächlich auf eine überproportionale Steigerung der Sozialausgaben - und nicht auf ein Absinken der volkswirtschaftlichen Wachstumsraten - zurückzuführen ist. Die folgende Tabelle vergleicht daher die $\mathrm{Zu}$ wachsraten der Sozialausgaben in Wahljahren und in Nicht-Wahljahren. Um den störenden Einfluß unterschiedlicher Inflationsraten auszuschalten, wird das Wachstum in konstanten Preisen (1975) verglichen ${ }^{17}$.

TABELLE 3 Durchschnittliche reale Wachstumsraten der Sozialausgaben in Wahljahren und Nicht-Wahljahren

\begin{tabular}{|c|c|c|c|c|}
\hline & $\begin{array}{l}\text { Samtliche } \\
\text { Jahre }\end{array}$ & Wahijature & Nicht-Wahljahse & $\begin{array}{l}\text { Differenz Waht } \\
\text { Jahre Nicht. } \\
\text { wahljahre }\end{array}$ \\
\hline $\begin{array}{l}\text { Gesamter } \\
\text { Zestraum } \\
\text { (1954-1978) }\end{array}$ & $69^{\prime \prime}$ & $86 \%$ & $63 \%$ & +23 \\
\hline $\begin{array}{l}\text { CDU gefuhrte } \\
\text { Regierungen } \\
\text { (1954-1969) }\end{array}$ & $73 \%$ & $92 \%$ & $66 \%$ & +26 \\
\hline $\begin{array}{l}\text { SPD/FDP } \\
\text { Koalition } \\
(1970-1978)\end{array}$ & $61 \%$ & $73 \%$ & $58 \%$ & +1.5 \\
\hline
\end{tabular}

Angesichts der zahlreichen über die Zeit variierenden Störfaktoren - etwa Rentnerzahlen - sollten nicht die unterschiedlichen Wachstumsraten verschiedener Regierungsperioden, sondern lediglich

17 Eine Umrechnung der laufenden Ausgaben in konstante Preise war mit dem vorhandenen Zahlenmaterial erst ab 1954 möglich (vgl. die Anhangtabellen). 
die Variationen in der Differenz der Wachstumsraten zwischen Wahljahren und Nicht-Wahljahren verglichen werden. Diese Differenzen zeigen, daß die CDU-gefuihrten Regierungen in deutlich stärkerem Maße zu einer Politik der Wahlgeschenke neigten, als die Regierungen der sozialliberalen Koalition (2.6 Prozentpunkte Differenz gegenüber 1.5). Erinnert man sich daran, daß ein Prozentpunkt zusätzlichen Wachstums einer Kostensteigerung von zunächst 146 Millionen DM (1950), später einer halben Milliarde (1960) und zuletzt (1978) 3 Milliarden entsprach, so erscheinen diese Zahlen nicht nur von akademischem Interes$\mathrm{se}^{18}$

Die Ergebnisse sind auch kaum als statistische Artefakte abzutun, denn sie unterstreichen nur auf quantitative Weise, was Hans-Peter Bank (1970) schon ähnlich durch eine Analyse der Gesetzgebung gezeigt hat. Bank untersuchte die jährlich verabschiedete Zahl sozialpolitischer Gesetze im Zeitraum 1949 bis 1968 und fand einen deutlichen Anstieg der gesetzgeberischen Tätigkeit in Wahljahren. Neben der Gesamtzahl der verabschiedeten Gesetze wuchs auch der Anteil der sozialen Leistungsgesetze in Annäherung an den Wahltermin, um im Jahr danach drastisch zu sinken und dann dem Wahlzyklus aufs neue zu folgen. Berechnet man aus Banks Zahlen Durchschnittswerte, so lassen sich seine Ergebnisse wie folgt zusammenfassen: In Nicht-Wahljahren betrug die Zahl der sozialen Leistungsgesetze durchschnittlich 7, in Wahljahren aber 18, und ihr Anteil an allen sozialpolitischen Gesetzen stieg von 39 auf 48 Prozent (Bank 1970: 101). Es wäre sicherlich reizvoll, Banks Analyse für die Regierungszeit der sozialliberalen Koalition zu replizieren.

Das vorherige Ergebnis einer für die CDU-Regierungszeit abgeschwächten Beziehung zwischen Sozialausgabensteigerung und volkswirtschaftlichem Wachstum legt nahe, daß die überproportionale Spendierfreudigkeit der Politiker in Wahljahren nicht auf einen besonderen Reichtum ökonomischer Ressourcen zurückgeführt werden kann. Um ein direktes Maß des Einklangs von volkswirtschaftlichem Ertrag und sozialpoliti-

18 Zum Vergleich: Die Gesamt-Ausgaben für Entwicklungshilfe beliefen sich 1977 auf $3.1,1978$ auf 3.8 Mrd. DM (Bundesministerium der Finanzen 1979: 198). schen Aufwendungen zu erhalten, wurden für die folgende Tabelle die jährlichen Differenzen zwischen beiden Wachstumsraten berechnet. Positive Zahlen deuten an, daß die Sozialleistungen schneller gewachsen sind als das Wirtschaftsprodukt. Da nun statt des Wandels über die Zeit zwei jährliche Wachstumsraten miteinander verglichen werden, stützt sich die Tabelle wieder auf nominale Zahlen zu laufenden Preisen, so daß drei zusätzliche Jahre untersucht werden können ${ }^{19}$.

TABELLE 4 Durchschnittliche Differenz zwischen Wachstumsraten der Sozialausgaben und des Sozialprodukts

\begin{tabular}{llll}
\hline & Wahljahre & $\begin{array}{l}\text { Nicht- } \\
\text { Wahljahre }\end{array}$ & $\begin{array}{l}\text { Sämtliche } \\
\text { Jahre }\end{array}$ \\
\hline $\begin{array}{l}\text { Gesamter } \\
\begin{array}{l}\text { Zeitraum } \\
(1951-1978)\end{array}\end{array}$ & $2.7(3.2)$ & $1.6(2.0)$ & $1.9(2.3)$ \\
$\begin{array}{l}\text { CDU geführte } \\
\text { Regierungen } \\
(1951-1969)\end{array}$ & $2.5(3.3)$ & $0.6(1.2)$ & $1.1(1.7)$ \\
$\begin{array}{l}\text { SPD/FDP } \\
\text { Koalition } \\
(1970-1978)\end{array}$ & $3.1(3.1)$ & $3.3(3.3)$ & $3.2(3.2)$ \\
\hline
\end{tabular}

Einmal mehr sollten wegen der verschiedenen Störvariablen nicht die phasenspezifischen Variationen zwischen den Regierungsperioden verglichen werden, sondern nur die Differenzen zwischen Wahljahren und Nicht-Wahljahren. Zwar wuchsen die Sozialausgaben allgemein in größerem Tempo als das Sozialprodukt (+1.9 Prozentpunkte), aber dieses Vorpreschen war in Wahljahren besonders ausgeprägt ( 2.7 Prozentpunkte). Wiederum bestätigt sich die allgemeine Tendenz nicht in gleicher Weise für die verschiedenen Regierungsperioden. War unter den CDU-geführten Regierungen die Loslösung der Sozialleistungen vom Tempo des wirtschaftlichen Wachstums in Wahljahren vierfach stärker als in Nicht-Wahljahren (2.5 gegenüber 0.6 Prozentpunkten Differenz), so zeigt sich für die Regierungszeit der sozialliberalen Koalition eine weitgehende Gleichverteilung, wobei die relative Beschleunigung der Sozialausgabensteigerung sogar in Nicht-Wahl-

19 Die Zahlen in Klammern beziehen sich auf den Zeitraum 1954-1978, um klarzustellen, daß der Ein- oder Ausschluß des Wahljahres 1953, für das reale Wachstumsraten hier nicht zur Verfügung standen, keinen grundlegenden Einfluß auf das Ergebnisbild hat. 
jahren etwas stärker war ( 3.3 im Vergleich zu 3.1 Prozentpunkten Differenz). Wenn es in der Bundesrepublik Regierungen gab, auf die Janowitz' Hypothesen zur Nachgiebigkeit demokratischer Entscheidungsträger gegenüber Konsumansprüchen der Wähler zutreffen, so sind es die CDURegierungen der funfziger und sechziger Jahre. Das bekannteste Einzelbeispiel für die Politik der Wahlgeschenke ist vermutlich das kurz vor den Wahlen 1965 eingeführte ,Pennälergehalt", das, wie oben beschrieben, 1967 wieder abgeschafft wurde.

Offen bleiben muß nach diesen Analysen die Frage, ob die gefundenen Unterschiede im sozialpolitischen Handlungsmuster verschiedener Regierungen in erster Linie eine Funktion ihrer unterschiedlichen parlamentarischen Mehrheiten oder ihrer parteipolitischen Orientierung sind. Zumindest für die Vergangenheit erscheint die Annahme einer besonderen Neigung konservativer Parteien zu sozialpolitischen Wahlgeschenken plausibel, da sie vermutlich ihrer Identifizierung als verläßlicher Anwalt sozialpolitisch interessierter Wählerschichten sehr viel weniger sicher sein konnten als ihre sozialdemokratischen Rivalen. Um solche Hypothesen verläßlicher beurteilen zu können, wären allerdings genauere Kenntnisse des sozialpolitischen Profils verschiedener Parteien notwendig. Noch wissen wir über die Grundlagen des Wachstums des Wohlfahrtsstaats, vor allem in vergleichender Perspektive, viel zu wenig. Gibt es feste sozialpolitische Präferenzmuster, die realisiert werden, sobald die betreffende Partei über ausreichende Mehrheiten verfügt? Oder sind die programmatischen Aussagen nur Lippenbekenntnisse, die in der Regierungsverantwortung zugunsten pragmatischen Taktierens und tagespolitischen ,Durchwurstelns“ in den Hintergrund treten? Für die Bundesrepublik würde ein Vergleich der sozialen Reformpläne der SPD in den fünfziger Jahren mit den Regierungsvorlagen des letzten Jahrzehnts für die Beantwortung dieser Fragen sicherlich wertvolle Hinweise geben können, aber ein solcher Vergleich würde den Rahmen dieses Aufsatzes sprengen. Die folgenden Abschnitte wenden sich vielmehr der Frage zu, ob die gegenwärtige Kritik am Wohlfahrtsstaat eine empirische Grundlage hat und ob sich Anzeichen einer Krise ausmachen lassen.

\section{Probleme und Krisensymptome}

Die Kritik am Wohlfahrtsstaat läßt sich auf einen einfachen Nenner bringen: Er ist zu teuer, $\mathrm{zu}$ ineffizient und daruber hinaus gefährlich (s. Heclo 1980). Mit dem hier zur Verfügung stehenden Material können diese Anschuldigungen nur grob mit Hilfe einiger Aggregatdaten und mit Hilfe der Ergebnisse diverser Meinungsbefragungen untersucht werden. Auf der Ebene der Aggregatdaten zeigt sich, daß der deutsche Wohlfahrtsstaat in der Tat zunehmend teuer geworden ist (vgl. Anhangtabelle A4). Die steuerlichen Abgaben haben sich zwischen 1950 und 1978 verdreifacht, während die Sozialversicherungsbeiträge fast verdoppelt wurden. 1950 muß ten die beschäftigten Arbeitnehmer im Durchschnitt noch bescheidene 12.5 Prozent ihres Einkommens für Steuern $(4.6 \%)$ und Sozialversicherungsabgaben ( $7.9 \%$ ) berappen. 1969 erreichte die Abgabenlast die 20 Prozent-Marke, und nur acht Jahre später übersprang sie bereis die Grenze von 30 Prozent (30.3\% 1977). Erst 1978 zeigte sich in diesem Aufwärtstrend ein Knick, als die Abzüge knapp unter die 30 Prozent-Marke $(29.7 \%)$ zurückfielen. Die gesetzlichen Beiträge zur Sozialversicherung, die in den fünfziger und sechziger Jahren mehrere Jahre lang unverändert geblieben waren, wurden seit 1965 mit nur drei Ausnahmen $(1970,1971,1978)$ jährlich angehoben ${ }^{20}$. Auch hier brachten erst die letzten drei Jahre einen Stillstand.

Die Tatsache, daß der Wohlfahrtsstaat teurer wurde, besagt allerdings noch nicht, daß er ,zu teuer" im Sinne einer unerträglichen Abgabenlast geworden ist. Folgt man Harold Wilensky (1976), so wird das Potential für einen ,tax/ welfare backlash" vor allem durch den Grad der „Sichtbarkeit“ (visibility) der Steuerabzüge bestimmt. Sozialversicherungsbeiträge werden nach seinen Untersuchungen von den Bürgern nicht als Steuer, sondern als eine Form des privaten Sparens wahrgenommen und zählen ebenso wie

20 Die in der Anhangtabelle A 4 berichtete Senkung der Beitragssätze ist das Ergebnis zwejer Veränderungen, der Zusammenlegung der Arbeiter- und Angestelltenbeiträge in der Berichterstattung und der Verschiebung der Kosten des Krankengeldes von den Kassen zu den Arbeitgebern durch die Einführung der Lohnfortzahlung. 
Verbrauchssteuern zu den ,unsichtbaren“ Abgaben, die Steuerrevolten weniger als die direkten Abzuige herausfordern. Ein Blick auf die Finanzierungsweise der deutschen Sozialleistungen zeigt, daß der Anteil der allgemeinen Steuermittel an den Gesamteinnahmen über die Jahre gesunken ist. Lag er in den fünfziger und frühen sechziger Jahren über 30 Prozent, so betrug er 1974 - das letzte Jahr, für das die diesbeziiglichen Statistiken des Internationalen Arbeitsamtes momentan zur Verfügung stehen - 24 Prozent. Im Sinne von Wilenskys' Kategorien müssen die höheren Kosten demnach nicht unbedingt zunehmend untragbar geworden sein. Die Abgabebereitschaft der Bevölkerung ist im übrigen wohl immer auch eine Funktion der Fähigkeit der Politiker, Zustimmung für ihre Steuerforderungen zu mobilisieren.

Der zweite Anklagepunkt der Ineffizienz bezieht sich darauf, daß der Wohlfahrtsstaat trotz steigender Kosten die drängendsten Notlagen nicht beseitigt. Die CDU hat diese Anschuldigung kürzlich als ,Neue Soziale Frage“ thematisiert. Demnach konzentriert sich die Sozialpolitik immer noch auf das inzwischen weitgehend gelöste Problem der Integration der Arbeiter, während neue Problemgruppen, die über kein Selbsthilfepotential und keine Verhandlungsmacht verfuigen, unberücksichtigt bleiben. Die Anklage wurde durch empirisches Material untermauert, wonach 6 Millionen Personen oder 9 Prozent aller Haushalte inmitten des allgemeinen Wohlstandes gemäß den Kriterien der Sozialhilfe in Armut leben (Geißler 1976: 27). Eine - von wissenschaftlichen Skrupeln allerdings nicht sonderlich berührte - Studie ging sogar soweit, 25 Prozent der Bevölkerung als arm zu erklären (Roth 1974: 76). Inzwischen haben sorgfältige Forschungsarbeiten des SPES-Projekts in Frankfurt und Mannheim gezeigt, daß auch Geißlers Zahlen der Nachprifung nicht standhalten ${ }^{21}$. Den SPES-Arbeiten zufolge leben 1 bis 2 Prozent der Bürger nach Sozialhilfekriterien in Armut, wobei ihre Zahl zwischen 1969 und 1974 von 600.000 auf 1 Million gestiegen ist (Kortmann 1976: 25, Klanberg 1978a: 139f, Klanberg 1978b: 174f). Dies sind sicherlich 1 Million Menschen zuviel, aber um auf die Ineffizienz

21 Vor allem, weil mit unrealistischen Annahmen bezüglich der Mietkosten gearbeitet wurde. des Wohlfahrtsstaates schließen zu können, bräuchten wir Zahlen, die das Ausmaß der Armut systematisch über die Zeit verfolgen, nicht nur einen Vergleich zwischen einem Prosperitätsjahr (1969) und einem Rezessionsjahr (1974).

Zeitreihen, die erlauben würden, einzuschätzen, wie treffsicher der Wohlfahrtsstaat seine verschiedenen Zielgruppen erreicht, sind natürlich äußerst schwierig zu erhalten. Als ein relativ einfaches Maß ließen sich jedoch Unterstütztenquoten berechnen, die angeben, welcher Prozentsatz der von einem bestimmten Problem betroffenen Bevölkerungsgruppen tatsächlich soziale Entschädigungen bezieht. An dieser Stelle ist die Berechnung solcher Quoten nur für die Arbeitslosenversicherung möglich. Hier ist der bundesrepublikanische Wohlfahrtsstaat nach dem verfügbaren Zahlenmaterial über die Zeit eher effizienter geworden. Wie in den fünfziger und sechziger Jahren, so erhielten auch in den letzten Jahren der angespannten Wirtschaftslage drei Viertel bis vier Fünftel der Erwerbslosen Arbeitslosengeld oder -hilfe. Die niedrigste Unterstütztenquote (63\%) hatte das Jahr 1973 zu verzeichnen. In zwei weiteren Jahren (1966 und 1974) fiel die Quote unter die 70 Prozent-Marke; in allen anderen bezogen drei Viertel oder mehr der Arbeitslosen staatliche Zahlungen ${ }^{22}$. Gleichzeitig ist das Niveau der Leistungen über die Zeit beträchtlich gestiegen (vgl. Tabelle 1). Heute liegt das Arbeitslosengeld bei 68 Prozent des vorherigen Nettolohns, während sich die Arbeitslosenhilfe auf 58 Prozent beläuft.

\section{Der dritte Vorwurf gegen den Wohlfahrtsstaat} ist, daß er zu den Problemen, die er bewältigen sollte, selbst beiträgt. So bremst angeblich ein verbesserter Kündigungsschutz die Einstellungsbereitschaft der Arbeitgeber und fördert damit die Arbeitslosigkeit; verbesserte Sozialversicherungsleistungen verteuern über die Erhöhung der Beiträge die Lohnkosten und veranlassen die Unternehmer zu arbeitssparenden Rationalisierungsmaßnahmen; ein Ausbau des Mieterschutzes

22 Die letzte verfügbare $\mathrm{Zahl}$ ist $82 \%$ für das Jahr 1977. Sämtliche angegebenen Quoten sind Berechnungen des Autors, die auf den Arbeitslosenzahlen in Anhangtabelle A 2 beruhen, sowie auf der errechneten Summe der vom Bundesministerium für Arbeit $(1970,1974,1977,1980)$ gegebenen Zahlen für die Leistungsempfänger des Arbeitslosengeldes und der Arbeitslosenhilfe. 
schreckt potentielle Investoren vom Wohnungsbau $\mathrm{ab}$ und treibt über die Verknappung des Wohnungsangebots die Mietkosten nach oben. Solche Behauptungen sind in politischen Auseinandersetzungen häufig zu hören ${ }^{23}$. Auf wissenschaftlicher Seite stammt der ehrgeizigste Versuch, zu einer Theorie der negativen Effekte des Wohlfahrtsstaates zu gelangen, wiederum von Morris Janowitz (1976). Nach Janowitz entwikkelt der Wohlfahrtsstaat gefährliche Nebenwirkungen im politischen, ökonomischen und sozialen Bereich. In der sozialen Sphäre trägt die zentralisierte und bürokratisierte Organisation der Sozialleistungen zur Zerstörung der sozialen Netzwerke - Verwandtschaft, Nachbarschaftsgruppen - bei, die nicht nur ein Selbsthilfepotential mit bedeutsamen Sicherungsfunktionen, sondern auch ein Element der sozialen Kontrolle überbordender individueller Aspirationen verkörpern. Im politischen Bereich führt die zunehmende Fusion von Markt- und Transfereinkommen zu diffuseren politischen Loyalitäten und damit zu knapperen, unbeständigeren parlamentarischen Mehrheiten und schwachen Regierungen. Im ökonomischen Sektor tragen die Sozialausgaben zu sinkenden Wachstumsraten bei, weil sie die Ressourcen von der Investition zum Konsum lenken, während gleichzeitig der für die (Um-)Verteilung zur Verfügung stehende Überschuß mit dem Ende der Nachkriegsexpansion schrumpft. Die infolge der Lockerung sozialer Kontrollen wachsenden Konsumansprüche fördern, in Verbindung mit der geringen Steuerungsfähigkeit schwacher Regierungen, wachsende Defizite des öffentlichen Haushalts, die ihrerseits die Inflation anheizen.

Janowitz' Arbeit ist zwar bezüglich des breit angelegten Versuchs zur theoretischen Verknüpfung diverser Entwicklungsprozesse beeindruckend, aber sie spezifiziert nur selten die Bindeglieder, die das Wachstum des Wohlfahrtsstaats mit den beobachteten Nebeneffekten vermitteln. Zumindest drei der behaupteten Beziehungen erschei-

23 Eine theoretische Ausarbeitung der beiden ersten Argumente hat kürzlich die F.D.P. des Saarlandes durch ihren Wirtschaftsfachmann, Prof. Stützel, versucht (vgl. Süddeutsche Zeitung 31.10./1.11.1977). Das dritte Argument hat des öfteren Kurt Biedenkopf vertreten. Eine zusammenfassende Diskussion verwandter Argumente gibt der Artikel von Strasser (1978). Die wohl radikalste Kritik für den Sektor des Gesundheitswesens stammt von Illich (1977). nen jedoch theoretisch plausibel und einer empirischen Überprüfung zugänglich: (1) Wo die Arbeitgeber, wie in der Bundesrepublik, in starkem Maße zur Finanzierung der Sozialleistungen herangezogen werden, bringt ein sozialpolitischer Ausbau in der Tat eine gesetzlich verordnete Bindung von Ressourcen mit sich, die sonst möglicherweise für Investitionen zur Verfügung stünden. (2) Politisch geforderte und gesetzlich verankerte sozialpolitische Verpflichtungen begünstigen im Kontext schrumpfender Steuereinnahmen in Rezessionsjahren die Finanzierung über öfentliche Verschuldung. (3) Steigende Haushaltsdefizite und ausgedehntere soziale Dienstleistungen - die, wie der tertiäre Sektor allgemein, lohnintensiv sind, aber nur geringe Produktivitätsfortschritte zeigen - tragen zu einem Nachfrageüberhang und damit zu zunehmender Inflation bei. Die folgenden, allerdings nur groben, Analysen untersuchen, ob sich diese Hypothesen für die Entwicklung des Wohlfahrtsstaats in der Bundesrepublik halten lassen.

Auf den ersten Blick erscheinen Janowitz' Uberlegungen mit den empirischen Daten im Einklang. Während der Anteil der Sozialausgaben am Sozialprodukt ständig gewachsen ist, sind die volkswirtschaftlichen Wachstumsraten kontinuierlich gesunken. Das stürmische Tempo von durchschnittlich 8 Prozent realen jährlichen Wachstums in den füfziger Jahren (Tennstedt 1976: 419), verlangsamte sich in den sechziger Jahren auf knapp 5 Prozent, um schließlich in den siebziger Jahren auf gemächliche 3 Prozent abzusacken (vgl. Anhangtabelle A 1). Die obigen Analysen zum Zusammenhang beider Wachstumsraten haben allerdings bereits gezeigt, daß das verlangsamte Tempo nur sehr bedingt auf das Wachstum der Sozialausgaben zurückgeführt werden kann $(r=.18)$. Jürgen Kohl (1980) konnte überdies zeigen, daß das Wachstum der sozialen Transferzahlungen nicht von einem Rückgang der öffentlichen Investitionen begleitet war, sondern daß die gleichzeitige Steigerung beider Ausgabearten den wachsenden Haushaltslücken zugrundeliegt. In Anlehnung an Janowitz' Überlegungen können wir hier darüber hinaus untersuchen, ob die volkswirtschaftlichen Investitionen insgesamt im Zuge des Wachstums der Sozialausgaben zurückgegangen sind. Wie Graphik 4 zeigt, bestand zwischen beiden Veränderungsraten tatsächlich eine Negativbeziehung. Wenn die Sozialleistungen in die Höhe gingen, 
wurden die Anlageinvestitionen gebremst ( $\mathrm{r}=$ -.23). Gleichzeitig waren steigende Sozialausgaben von einer höheren öffentlichen Verschuldung $(\mathrm{r}=.32)^{24}$ und von zunehmenden Inflationsraten begleitet $(r=.15)^{25}$. Die Zeichen der Korrelationsbeziehungen sind somit sämtlich in der von Janowitz' postulierten Richtung, aber ihre Stärke ist wesentlich weniger ausgeprägt, als es die theoretischen Formulierungen nahelegen. Die Anteile der erklärten Varianz reichen lediglich von 2 Prozent (Inflationsrate) und 5 Prozent (Investitionszuwachs) zu einem Spitzenwert von 10 Prozent im Fall der öffentlichen Verschuldung, und es wäre sicherlich vermessen, auf der Grundlage dieser groben bivariaten Analysen weitreichende Schlußfolgerungen anzustellen, ohne die Fülle von anderen Variablen in Betracht zu ziehen, die solche grundlegenden GröBen der Wirtschaftsentwicklung beeinflussen.

GRAPHIK 2 Wirtschaftswachstum und Sozialausgabenwachstum

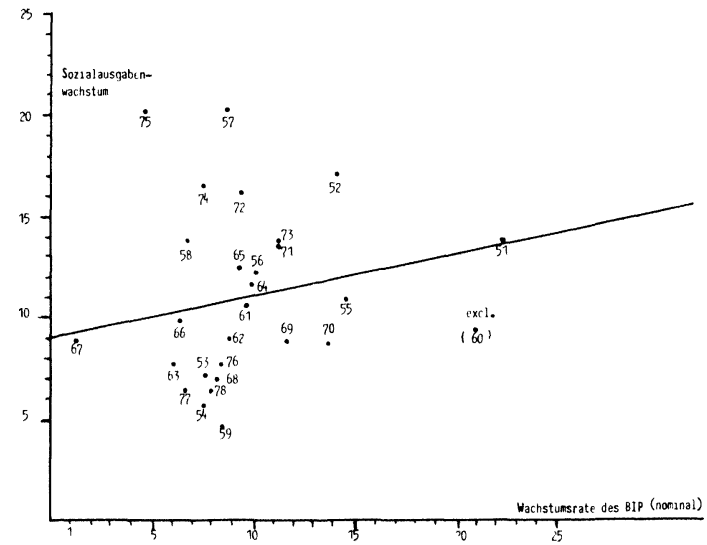

24 Die öffentliche Verschuldung ist hier durch die Kreditfinanzierungsquote gemessen, das ist die Differenz zwischen Staatsausgaben (inkl. Zinsen, exkl. Tilgung) und Staatseinnahmen, ausgedrïckt als Prozentsatz der Ausgaben. Negative Daten zeigen Überschüsse an (vgl. Anhangtabelle A 2). Ich danke Jürgen Kohl für die Bereitstellung der von ihm im HIWED Projekt gesammelten Daten.

25 Das Wachstum der Sozialausgaben wurde für diese Analyse in konstanten Preisen gemessen, um zu gewährleisten, daß die Inflationsrate nicht auf beiden Seiten der Gleichung erscheint. Schließt man das im Regressionsdiagramm als „Ausreißer" erscheinende Jahr 1957 von der Betrachtung aus, so erhöht sich die Korrelation auf $r=.30$, womit auch nur $9 \%$ der Varianz der Inflationsrate in den übrigen Jahren erklärt werden.
GRAPHIK 3 Sozialausgabenwachstum und Inflation

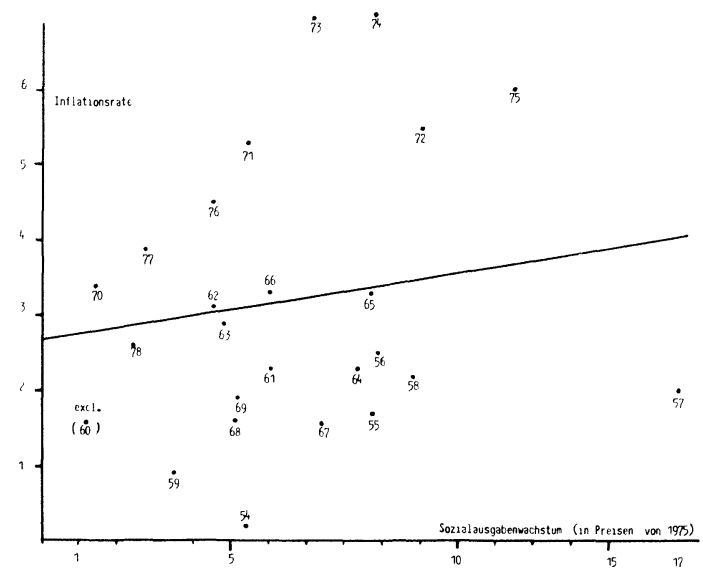

GRAPHIK 4 Sozialausgabenwachstum und Investionen

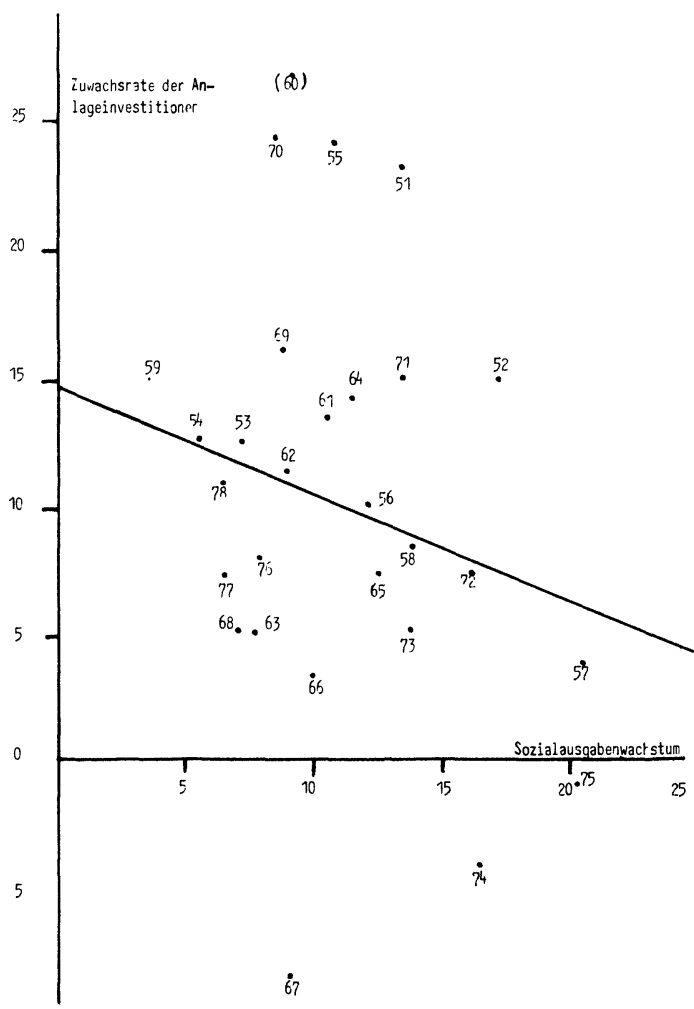

Die Ebene der Aggregatanalyse mag gefährliche Nebeneffekte der Expansion des Wohlfahrtsstaats möglicherweise aber auch verbergen. Wenn etwa steigende Kosten der sozialpolitischen Leistungen wirklich die Grenzen der steuerlichen 
GRAPHIK 5 Sozialausgabenwachstum und Staatsverschuldung

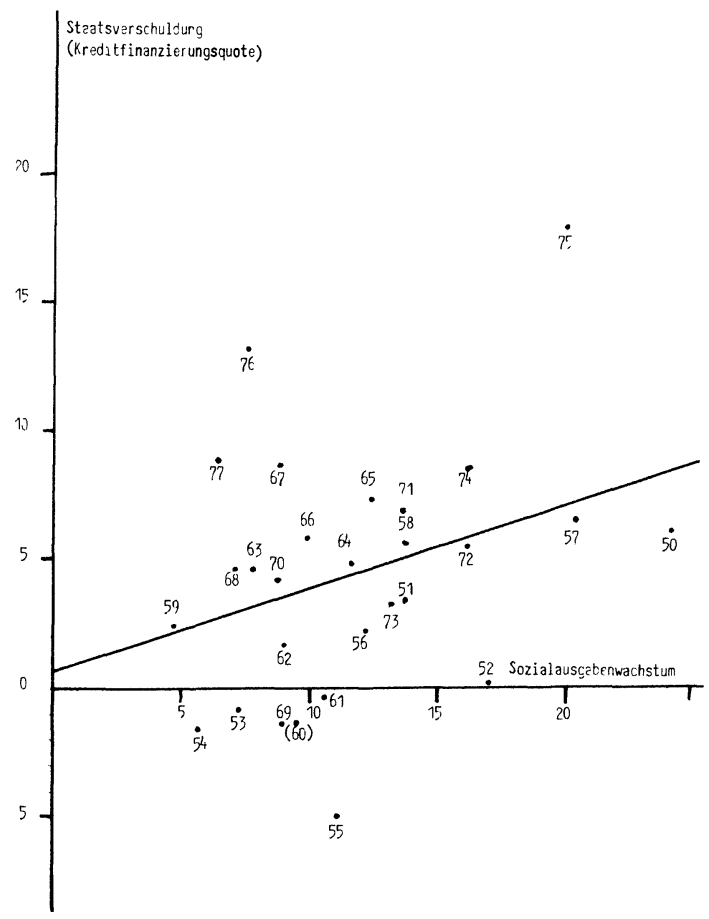

Belastbarkeit streifen und wachsenden Widerstand der Bürger oder gar neue soziale Konflikte herausfordern sollten, so ließen sich solche Entwicklungen vermutlich besser an sich wandelnden Meinungsströmungen ablesen als anhand ökonomischer Makrogrößen. Zwei Soziologen haben kürzlich versucht, das Potential für die Entwicklung neuer sozialer Konfliktstrukturen mit der Expansion des Wohlfahrtsstaats in Verbindung zu bringen. Harold Wilensky (1975) vertritt die Hypothese, daß die zunehmende Steuerlast für die neue ,Mittelmasse" der Bürger - die sich aus den gelernten Arbeitern und den Angestellten zusammensetzt - Ressentiments gegen den Wohlfahrtsstaat und gegen die von den Sozialleistungen profitierenden unteren Schichten Auftrieb geben wird. Ausgehend von Max Webers Klassentheorie postuliert M. Rainer Lepsius (1979) das Aufkommen neuer Konflikte zwischen ,Versorgungsklassen“, die sich gemäß den ungleichen Zugangschancen zum System öffentlicher Güter und Transferleistungen strukturieren. Vor allem das Rentenversicherungssystem könnte in der Bundesrepublik typische Versorgungslagen konstituieren, da es zum einen die Geschlechter, zum anderen die
Erwerbstätigen und die Nicht-Erwerbstätigen unterschiedlich privilegiert. So sind Frauen als Berufstätige zwar beitragspflichtig, arbeiten aber selten lange genug, um die Anwartschaftszeit von 15 Jahren als Voraussetzung der Rentenzahlung zu erfüllen. Konflikte zwischen den erwerbstätigen Beitragszahlern und den Rentnern sind abzusehen, wenn der demographische Wandel den Anteil der Alten weiter anwachsen läßt, so daß der gegenwärtig bei 18 Prozent des Lohns (inkl. Arbeitgeberanteil) liegende Beitragssatz weiter steigt.

Umfragedaten für eine Einschätzung der gegenwärtigen Bedeutung dieser neuen Konfliktlinien stehen leider nur in unzureichendem Maße zur Verfuigung. Die hier herangezogenen Erhebungen erlauben lediglich drei vorläufige Schlußfolgerungen: (1) Sozialausgaben und insbesondere die Altersrenten werden allgemein als dringlich eingeschätzt und treffen auf weitgehende Zustimmung. Zwischen 1975 und 1978 ist der Prozentsat $z$ derjenigen, die meinen, daß die sozialen Leistungen ,,auf keinen Fall" gekürzt werden sollten, sogar gestiegen (von 67 auf 73 Prozent, wenn nach Geldleistungen gefragt wurde, und von 71 auf 76 Prozent, wenn es um Sozialinvestitionen ging $-\mathrm{s}$. Bundesministerium für Arbeit 1980: 48). Bei der Frage nach vorrangigen Problemen wird der finanziellen Sicherheit im Alter gewöhnlich hohe Priorität zugebilligt (Klingemann/Taylor 1978: 129, Institut für Demoskopie 1974: 132). (2) Das System der Pflichtversicherung stößt auf allgemeine Zustimmung und wird von der überwältigenden Mehrheit der Bürger alternativen freiwilligen Sicherungsformen vorgezogen. Wie Tabelle 5 zeigt, gilt dieser Befund für verschiedene Zeitpunkte, wobei eine Einschätzung der Fluktuation der Meinungen über die Zeit wegen der stark variierenden Fragestellungen leider kaum möglich ist.

(3) Auch wenn die Befragten daran erinnert werden, daß die öffentlichen Sicherungssysteme kostspielig sind, ziehen sie diese teuere, aber verläßliche Form der Sicherung alternativen privaten Lösungen vor. So meinten 195779 Prozent der Bürger, daß sie lieber in einem Land mit hohen Steuern, aber ausgebauter sozialer Sicherung leben würden, als in einem Land mit niedrigen Steuern, wo der Staat nur den Bedürftigen zur Seite springt und der Mehrzahl der Bürger die Vorsorge selbst überläßt. Zur letzten 
TABELLE 5 Zustimnung zum System der Pflichtversicherung in verschiedenen Meinungsbefragungen

\begin{tabular}{|c|c|c|c|c|c|}
\hline & 1950 & $1963 a$ & $1963 b$ & 1977 & 1978 \\
\hline $\begin{array}{l}\text { Dem Pflichtversi- } \\
\text { cherungssystem } \\
\text { zustimmend }\end{array}$ & 72 & 91 & 90 & 79 & 82 \\
\hline $\begin{array}{l}\text { Präferenz für } \\
\text { freiwillige Systeme }\end{array}$ & 17 & 5 & 3 & 18 & 14 \\
\hline $\begin{array}{l}\text { Unentschieden } \\
\text { /ohne Antwort }\end{array}$ & 10 & 4 & 7 & (3) & (4) \\
\hline Bezug der Frage & $\begin{array}{l}\text { Kranken- } \\
\text { versiche- } \\
\text { rung }\end{array}$ & \multicolumn{2}{|c|}{$\begin{array}{l}\text { Pflichtversicherung } \\
\text { allgemein }\end{array}$} & \multicolumn{2}{|c|}{$\begin{array}{l}\text { Pflichtversiche- } \\
\text { rung allgemein }\end{array}$} \\
\hline Quelle & $\begin{array}{l}\text { Institut } \\
\text { für De- } \\
\text { moskopie } \\
1956: \\
230 \text { (aus } \\
\text { der Ta- } \\
\text { belle be- } \\
\text { rechnet) }\end{array}$ & \multicolumn{2}{|c|}{$\begin{array}{l}\text { Kaufmann } 1969 \text { : } \\
107\end{array}$} & \multicolumn{2}{|c|}{$\begin{array}{l}\text { Bundesministe- } \\
\text { rium für Arbeit } \\
1980: 41\end{array}$} \\
\hline
\end{tabular}

\section{Die Fragen}

1950 Wurden Sie, wenn morgen die Kranken-Versicherungspflicht aufgehoben wirde, austreten oder freiwillig darin bleiben? $\mathbf{N}=$ ?; Kassenmitglieder

1963a) Finden $S_{1 e}$ es richtıg, daß die meisten Leute pflichtversichert sind, oder sollte keiner dazu gezwungen werden? $\mathrm{N}=1188$; Versicherte.

1963b) Wurden Sie aus der Sozıalversıcherung austreten, wenn Sie alle von Ihnen bisher bezahlten Beitrage zuruckbekamen? $\mathrm{N}=1188$; Versicherte.

1977 (Zustımmung $z u$ einer der folgenden Meınungsauberungen:)

$1978-$ Wir sind mit unserem System der sozialen Sicherung auf dem richtigen Weg. Es sichert bei Alter, Krankheit und anderen Notlagen, ohne den einzelnen zu bevormunden.

- Das System der sozialen Sicherung geht bet uns viel zu weit. Es betreut den Bürger zu stark und nimmt ihm zuviel eigene Verantwortung weg.

Lösung möchten sich lediglich 14 Prozent der Befragten bekennen (Institut für Demoskopie 1965: 416). In gleicher Weise sagten 197464 Prozent der Respondenten, sie würden es vorziehen, hohe Krankenversicherungsbeiträge zu zahlen und dabei die Gewißheit zu haben, im Krankheitsfall versichert $\mathrm{zu}$ sein, als geringe Beiträge zu zahlen und einen Teil des Risikos selbst zu tragen. Wiederum äußerten nur 14 Prozent eine Präferenz für die zweite Lösung (Institut für Demoskopie 1976: 184) ${ }^{26}$. Im Gegensatz zu Wilenskys Vorstellung einer Revolte gegen den Wohlfahrtsstaat unter den Angehörigen der „Mittelmasse“ war der Anteil der für private Sicherung Votierenden in der letzten Untersuchung unter den gelernten Arbeitern mit 10 ge-

26 Der Rest war in beiden Befragungen unentschieden. genüber 11 Prozent sogar etwas niedriger als unter den ungelernten 27 .

In den hier herangezogenen Umfragen ließ sich lediglich ein Beispiel finden, in dem die Verteilung der Antworten Wilenskys Thesen entspricht. Wie Tabelle 6 zeigt, ist der Anteil derjenigen, die lieber selbst entscheiden würden, ob sie sich versichern wollen oder nicht, zwischen 1975 und 1978 allgemein angestiegen, wobei das Bedürfnis nach größerer Wahlfreiheit am stärksten unter den gelernten Arbeitern ( +9 Prozentpunkte) und den Landwirten $(+15)$ wuchs.

TABELLE 6 Zustimmung zum System der sozialen Pflichtversicherung 1975 und 1978 (Prozentsatz der mit den folgenden Meinungen übereinstimmenden Befragten)

\begin{tabular}{|c|c|c|c|c|c|c|}
\hline \multirow[b]{2}{*}{$\begin{array}{l}\text { Bevolker urg im } \\
\text { wahlfahgen After }\end{array}$} & \multicolumn{3}{|c|}{$\begin{array}{l}\text { Der Staat garantiert jedem eine } \\
\text { ausreichende Sicherung Die } \\
\text { Kosten dafur werden in Form } \\
\text { von Steuern und Betragen durch } \\
\text { alle Burger entsprechend der } \\
\text { Hohe thes Einkommens aufge- } \\
\text { bracht }\end{array}$} & \multicolumn{3}{|c|}{$\begin{array}{l}\text { Jeder kann selbst bestimmen, } \\
\text { ob und inwieweit er sich und } \\
\text { seine Famile fur Krankheits- } \\
\text { falle, Arbeitstosigkelt, Alter } \\
\text { etc. versichern will Wenn er } \\
\text { sich nicht versichert, um Ber- } \\
\text { trage zu sparen, muß er das } \\
\text { Risiko auch sebst tragen. }\end{array}$} \\
\hline & $\begin{array}{c}1975 \\
77\end{array}$ & $\begin{array}{l}\text { (Differenz) } \\
(-3)\end{array}$ & $\begin{array}{c}1978 \\
74\end{array}$ & $\begin{array}{c}1975 \\
20\end{array}$ & $\begin{array}{l}\text { (Differenz) } \\
(+4)\end{array}$ & $\begin{array}{c}1978 \\
24\end{array}$ \\
\hline Ungelernte & 81 & $(-3)$ & 78 & 19 & $(+2)$ & 21 \\
\hline Facharbetter & 87 & $(-12)$ & 75 & 13 & $(+9)$ & 22 \\
\hline $\begin{array}{l}\text { Angesteltte (Nicht- } \\
\text { fuhrungspositionen) }\end{array}$ & 79 & $(-4)$ & 75 & 21 & $(+3)$ & 24 \\
\hline $\begin{array}{l}\text { Beamte (einfache, } \\
\text { nuttlere, gehobene) }\end{array}$ & 82 & $(-5)$ & 77 & 17 & $(+4)$ & $2 \mathrm{I}$ \\
\hline $\begin{array}{l}\text { Angestellte und Be- } \\
\text { amte in fuhrenden } \\
\text { Positionen }\end{array}$ & 70 & $(+1)$ & 71 & 29 & $(-2)$ & 27 \\
\hline Klenere Selbstanduge & 69 & $(-1)$ & 68 & 29 & $(0)$ & 29 \\
\hline $\begin{array}{l}\text { Grobere Selbst andige } \\
\text { und freiberuflich Ta- } \\
\text { uge }\end{array}$ & 62 & $(-4)$ & 58 & 38 & $(+3)$ & 41 \\
\hline Landwirte & 87 & $(-20)$ & 67 & 13 & $(+15)$ & 28 \\
\hline
\end{tabular}

Quelle: Bundesministerium für Arbeit (1980: 43).

Aus diesen wachsenden Forderungen nach größeren Entscheidungsspielräumen kann allerdings kaum auf eine beginnende Steuerrevolte der „Mittelmasse“ geschlossen werden. Wie Tabelle 7 zeigt, erklären sich gelernte Arbeiter und Angestellte sogar seltener bereit, eine Steuerpartei zu unterstuitzen, als es die ungelernten Arbeiter tun (27 und 25 gegenüber 31 Prozent).

Insgesamt meinten 56 Prozent der Befragten, daß sie eine Steuerpartei nicht wählen würden, während sich 20 Prozent als desinteressiert bezeichneten. 5 Prozent erklärten sich gewillt, eine solche Partei ,auf jeden Fall“" zu wählen (Bun-

27 Allerdings war die Zustimmung zum bestehenden System dafür unter den gelernten Arbeitern seltener. Die Ergebnisse sind also nicht eindeutig. 
TABELLE 7 Bereitschaft zur Wahl einer Steuerpartei 1978

\begin{tabular}{ll}
\hline & $\begin{array}{c}\text { Prozentsatz derjenigen, die } \\
\text { Wahlbereitschaft bekunden }\end{array}$ \\
\hline Wahlbevölkerung & $21(5 \%$, ,auf jeden Fall“, \\
Ungelernte Arbeiter & $31 \quad$ 16\%, ,vielleicht“) \\
Facharbeiter & 27 \\
Angestellte & 25 \\
Beamte & 20 \\
Selbständige & 33 \\
Landwirte & 26 \\
\hline
\end{tabular}

Quelle: Bundesministerium für Arbeit (1980: 63).

desministerium für Arbeit 1980: 61). Inzwischen wissen wir, daß solche Bereitschaftserklärungen mit dem tatsächlichen Erreichen der Fünf-Prozentgrenze nicht viel zu tun haben. Die Bürgerpartei der Steuergegner hat sich, nachdem sie im nordrhein-westfälischen Landtagswahlkampf weit unter 1 Prozent der Stimmen geblieben ist, stark zerstritten und kämpft mittlerweile um ihr Überleben. Auch ihre Aussichten für die Zukunft scheinen angesichts der Tatsache, daß der Anteil derjenigen, die das deutsche Steuersystem für ungerecht halten, zwischen 1975 und 1978 drastisch von 44 auf 29 Prozent gesunken ist (Bundesministerium für Arbeit 1980: 59), keineswegs positiv.

Eine in Anlehnung an Wilensky durchgeführte Analyse der Einstellungen zum Wohlfahrtsstaat von Franz Urban Pappi (1976) konnte ebenfalls keine Hinweise auf neue Konfliktstrukturen finden, die den Boden für neue politische Organisationsformen abgeben könnten. Nach Pappis Untersuchung reflektierten die Einschätzungen des Wohlfahrtsstaates weitgehend den alten Konflikt zwischen Unternehmern und Arbeitern, wobei Angestellte und Beamte stärker der positiven Meinung der Arbeiter zuneigen. Für wachsende Differenzierungen innerhalb der Gruppe der abhängig Erwerbstätigen ergaben sich keine Anzeichen. Wie Pappi berichtet, haben wahlsoziologische Untersuchungen allgemein eine wachsende Angleichung des Wahlverhaltens unter den Unselbständigen festgestellt. Als Fazit der Umfrageergebnisse läßt sich demnach festhalten, daß es zwar zunehmend Forderungen nach einer gröBeren Flexibilität der sozialen Sicherheitssysteme geben mag, die für individuelle Optionen mehr Raum bieten würde, daß sich überzeugen- de Belege für ein wachsendes Legitimitätsdefizit des gegenwärtigen Systems aber nicht finden lassen.

Fehlende Anzeichen wachsender Unzufriedenheit auf der Ebene von Massendaten bedeuten noch nicht, daß die Vorstellung zunehmender Konflikte um den Wohlfahrtsstaat eine Schimäre sein muß. Möglicherweise haben die Krisendiagnosen ihre Grundlage in einer wachsenden Uneinigkeit unter Meinungsfuhrern, die - entsprechend der These vom "two step flow of communication" - erst mit einer gewissen Verzögerung auch auf die breite Bevölkerung übergreift. Hier können dazu nur einige kurze Beobachtungen angestellt werden, die sich auf die Einstellungen von zwei Gruppen potentieller Meinungsführer beziehen, nämlich Sozialwissenschaftler und Politiker.

Unter den Sozialwissenschaftlern hat der Wohlfahrtsstaat in den letzten Jahren erhöhte Aufmerksamkeit auf sich gezogen, eine Tatsache, die manche Beobachter schon von einer ,Soziologisierung" der Sozialpolitik - nach einer früheren Phase der Ökonomisierung - sprechen läßt (Zöllner 1980: 176). Vereinfachend lassen sich vier Ansätze der deutschen Soziologie der Sozialpolitik unterscheiden. Zwei Gruppierungen mit einer eher pragmatischen Orientierung stehen dabei zwei Schulen gegenüber, die den Wohlfahrtsstaat auf sehr viel grundlegendere Weise in Frage stellen. Die erste pragmatisch ausgerichtete Gruppe geht von den bestehenden Strukturen aus und versucht, zu einer Rationalisierung des staatlichen Sozialleistungssystems beizutragen. Bei aller Heterogenität ist den Vertretern dieser Richtung - etwa Christian von Ferber (1971), Franz-Xaver Kaufmann (1973), Florian Tennstedt (1977) und, an herausragender Stelle, Wolfgang Zapf (1976) - das Bestreben gemeinsam, sozialpolitische Entscheidungen auf eine verbesserte Kenntnis der Verteilung typischer Lebenslagen und Bedürfnisstrukturen $\mathrm{zu}$ gründen und Instrumente zur genaueren Effizienzkontrolle bestehender Maßnahmen zu entwickeln. Ihr Ziel ist die Förderung einer aktiven Sozialpolitik, die mehr auf Vorbeugung als auf nachträgliche Hilfe ausgerichtet ist.

Eine zweite, schon grundsätzlichere Perspektive wird vor allem von Bernhard Badura und Peter Gross (1976) vertreten. Auch sie sind um eine 
Effizienzsteigerung sozialpolitischer Maßnahmen bemüht, versprechen sie sich aber am wirksam. sten von der Ergänzung wohlfahrtsstaatlicher Aktivitäten durch alternative Formen der Sicherung. Die Ausdehnung des staatlich reglementierten und professionalisierten Sozialgeschäfts hat für sie eine fortschreitende Klientelisierung der Bevölkerung in die Wege geleitet, der es durch eine Reaktivierung des Selbsthilfepotentials der sozialen Netzwerke entgegenzuwirken gilt. Über die Partizipation am sozialpolitischen Entscheidungsprozeß hinaus fordern sie eine stärkere Beteiligung der Klienten an der Bereitstellung der Leistungen. Ihre Zielvorstellung ist es, den passiven Konsumenten staatlicher Dienste in stärkerem Maße selbst zum Produzenten von sozialer Sicherheit zu machen.

Ähnliche Vorstellungen werden von Autoren wie Horst Baier (1976) und Helmut Schelsky (1978) in eine stärker theoretisch als pragmatisch orientierte Kritik des Wohlfahrtsstaats eingearbeitet. Beide Autoren betonen die politischen Nebeneffekte der sozialpolitischen Expansion, die für sie wegen zweier sich ergänzender Entwicklungstendenzen die Gefahr eines neuen Autoritarismus heraufbeschwört. Zum einen dehnen die politischen Eliten auf der Suche nach neuen Legitimitätsquellen - zu der sie nach Baier der Bedeutungsverlust traditioneller Legitimierungsweisen im Rahmen des Niedergangs des bürgerlichen Nationalstaats veranlaßt - den Einflußbereich des Staates ständig aus und verringern damit den für die individuelle Lebensgestaltung verbleibenden Spielraum. Zum anderen transformiert die Institutionalisierung des Rechtsanspruchs auf staatliche Leistungen die Verhaltensweisen der Bürger, die sich, anstatt aktiv nach individuellen Lösungen zu suchen, immer stärker auf staatliche Hilfen verlas. sen. Gemeinsam produzieren diese beiden eng zusammenhängenden Prozesse eine wachsende Kluft zwischen den neuen ,Verteilungseliten“ und ihren Versorgungsbürokratien einerseits und der in makrosoziale Betreuungs- und Versorgungseinheiten gegliederten Bevölkerung andererseits. Um diesen für die Bewahrung bürgerlicher Entfaltungsspielräume und gesellschaftlicher $D y$. namik gefährlichen Prozeß zu stoppen, muß der Einflußbereich des Staates begrenzt, die Fähigkeit zur Selbsthilfe dagegen gestärkt werden.

\section{$\mathrm{Zu}$ völlig anderen Schlußfolgerungen kommt auf} der Basis ähnlicher Beobachtungen eine vierte
Denkrichtung, die in Deutschland vor allem durch Claus Offe (1972) repräsentiert wird. Offe stimmt mit Baier und Schelsky darin überein, $\mathrm{da} ß$ individuelle Lebenschancen zunehmend von staatlichen Entscheidungen bestimmt werden, aber die sozialpolitischen Aktivitäten sieht er im Zusammenhang eines weitgehenden Interventionsverzichts des Staates, der nicht nur die kapitalistische Produktionsweise unverändert läßt, sondern auch am Fortbestand ausgedehnter Armutsinseln inmitten des allgemeinen Wohlstandes nichts ändert. Die Unfähigkeit des Wohlfahrtsstaats zum wirksamen Aufgriff elementarer Bedürfnisse ist nach Offe mit grundlegenden Strukturmerkmalen des politischen Systems ,spätkapitalistischer" Gesellschaften verknüpft. Auf der ,Input-Seite“ ist die Artikulation und Repräsentation von Bedürfnissen eingeschränkt, da die Fusion von Markt- und Transfereinkommen zur Ersetzung der einstigen Klassenparteien durch konfliktscheue und integrationsorientierte Volksparteien gefuihrt hat und da allgemeine Bedürfnisse, die wenig organisations- oder konfliktfahig sind, im System der Interessengruppenpolitik unberücksichtigt bleiben. Auf der ,,Output"-Seite haben drei zentrale Systemprobleme - wirtschaftliches Wachstum, Sicherheit nach außen und Sicherung der Massenloyalität - im politischen Handeln der Regierungen Priorität, so daß Bedürfnisse mit geringerer politischer Brisanz - etwa von Hausfrauen, Kindern, Rentnern etc. - vernachlässigt bleiben. $\mathrm{Zu}$ wirksameren Eingriffen des Staates in die primäre Verteilung der Lebenschancen in kapitalistischen Gesellschaften und dem notwendigen Ausbau der Sozialleistungen trägt nach dieser Einschätzung am besten eine Mobilisierungsstrategie bei, in deren Rahmen sich Teile der professionalisierten Dienstleistungsproduzenten mit der Klientel in den vernachlässigten Notstandsbereichen verbün$\operatorname{den}^{28}$.

28 Trotz seiner kritischen Einschätzung des Wohlfahrtsstaats in "spätkapitalistischen" Gesellschaften unterscheidet sich Offe von Kritikern der orthodoxen Linken, da er die relative Autonomie des Staats und die zunehmende Unfruchtbarkeit einer Klassenanalyse der modernen westeuropäischen Gesellschaften betont. Als Beispiel einer orthodox-marxistischen Kritik des Wohlfahrtsstaates vgl. den oft $\mathrm{zi}^{-}$ tierten Aufsatz von Müller/Neusüss (1970). Wegen der geringen Repräsentanz und Einflußkraft marxistischer Analysen wurde auf sie an dieser Stelle, an der es um die widerstreitenden Standpunkte potentieller Meinungseliten in der Bundesrepublik geht, nicht näher eingegangen. 
Vor dem Hintergrund der fast völligen Vernachlässigung der Sozialpolitik durch die Soziologie der sechziger Jahre mag die Herauskristallisierung konträrer sozialwissenschaftlicher Betrachtungsweisen als Beginn grundlegender Konflikte interpretiert werden. Mindestens ebenso denkbar ist aber, daß die Belebung der wissenschaftlichen Debatten zur Entwicklung einer Theorie des Wohlfahrtsstaates beiträgt, die neben den politisch gewollten Primäreffekten auch seine Nebenwirkungen thematisiert und damit zu einer Erhöhung sozialpolitischer Steuerungskapazitäten beiträgt. Insofern stehen konkurrierende sozialwissenschaftliche Entwürfe möglicherweise am Anfang einer verbesserten ,,sozialen Kontrolle" des Wohlfahrtsstaates im Sinne von Janowitz ${ }^{29}$.

Einige der sozialwissenschaftlichen Denkanstöße haben mittlerweile auch in der politischen Arena ein Echo gefunden. So waren verschiedene der hier zur ersten Gruppe der Pragmatiker gezählten Soziologen in beratender Funktion an der regierungsamtlichen Planung der Sozialpolitik beteiligt. Einige Bundesländer haben den $\mathrm{Ge}$ danken der Entprofessionalisierung und Aktivierung der Klienten aufgegriffen und experimentieren mit der Unterstützung von ,Sozialstationen", das sind von freien Verbänden getragene Dienstleistungszentren, deren Personal Hilfe „,vor Ort" leistet - etwa in den Privathaushalten alleinstehender alter Menschen - und versucht, die Nachbarschaft in die Dienstleistungen einzubeziehen. Helmut Schelsky war mit seiner These von der zunehmenden Betreuung und fürsorglichen Entmündigung der Bürger begehrter Redner auf verschiedenen Tagungen der Unionsparteien, und Offes Thesen der Vernachlässigung schlecht organisationsfähiger Gruppen sind bereitwillig von Teilen der CDU aufgegriffen worden, die die „Neue Soziale Frage" formuliert und zum Bestandteil des Parteiprogramms gemacht haben (s. Geißler 1976).

Die „Neue Soziale Frage“ enthält als Ausarbeitung einer neuartigen Perspektive vielleicht am

$29 \mathrm{Vgl}$. in diesem Zusammenhang den faszinierenden Pionierversuch von Zapf (1978), eine empirisch fundierte Theorie der für verschiedene Sektoren der Wohlfahrtsproduktion jeweils effizientesten Mischung der vier Produktionsfaktoren, Bürokratien, Assoziationen, Märkte und private Haushalte, zu entwickeln. ehesten die Wurzeln für eine künftige Ideologisierung sozialpolitischer Auseinandersetzungen. Allerdings gibt es anscheinend innerhalb der CDU selbst zwei rivalisierende Interpretationen. Die von Vertretern der Sozialausschüsse der $\mathrm{Par}$ tei vorgebrachte Auslegung wirkt, wenn man sie des Wortgeklingels politischer Schaukämpfe entkleidet, eher konventionell. Wegen des historischen Ansatzes der Sozialpolitik an der Arbeiterfrage - so lautet das Argument - steht der Ersatz des Arbeitseinkommens auch heute noch im Vordergrund sozialer Maßnahmen, obwohl die Arbeiter wegen ihres „Besitzes“ an Arbeit und der Verhandlungsmacht der Gewerkschaften inzwischen eher zu den privilegierten Gruppen zählen. Nötig seien sozialpolitische Reformen, die sich vom Gedanken des Lohnersatzes lösen und sich auf außerhalb des Arbeitsmarktes stehende Gruppen, die weder über ein zu ersetzendes Einkommen noch über politische Repräsentation verfügen, konzentrieren. In dieser Interpretation wird zwar einer Verlagerung des sozialpolitischen Schwerpunkts von der Erwerbsbevölkerung zu den Nicht-Erwerbstätigen das Wort geredet, aber eine Kürzung der traditionellen Leistungen wird nicht gefordert. Wesentlich radikaler ist dagegen die Interpretation, die Kurt Biedenkopf vorbringt. Für ihn repräsentiert die ,Neue Soziale Frage“ einen sozialpolitischen Neubeginn, der von der infolge der Einkommenssteigerung gewachsenen Fähigkeit der Erwerbstätigen zur Eigenverantwortung ausgeht. Die Sozialpolitik sollte nach seiner Meinung die Wohlfahrtsproduktion entstaatlichen und sich auf die wirksame Garantie einer Mindestsicherung gegen Armut konzentrieren, statt eine Verantwortung für die Sicherung des Lebensstandards derjenigen zu übernehmen, die aufgrund ihrer Marktposition oder Verhandlungsmacht für sich selbst sorgen können. Biedenkopfs Ziel ist es, der Privatinitiative und dem Marktmechanismus durch eine Einschränkung der Staatstätigkeit, vor allem im Wohnungssektor, soviel Spielraum wie möglich zu lassen (s. Süddeutsche Zeitung 15./16.1.77).

Sollten sich Biedenkopfs Vorstellungen in der Union durchsetzen, so wäre eine Polarisierung der sozialpolitischen Diskussionen kaum zu vermeiden, denn die jüngst veröffentlichten Reformvorschläge der Gewerkschaften und der Sozialdemokraten haben ein gänzlich anderes Gesicht. Die Pläne der Wehner-Kommission zur Renten- 
form sahen ursprünglich die Ausdehnung der Pflichtversicherung auf die Freiberuflichen und Selbständigen sowie eine staatliche Garantie der Finanzkraft der Rentenversicherung vor. Zwar wurden beide Vorschläge vom Parteivorstand nicht übernommen, aber, dem Urteil politischer Beobachter zufolge, war das eher der Rücksicht auf den Koalitionspartner als abweichenden sozialpolitischen Konzeptionen zuzuschreiben (s. Suddeutsche Zeitung 26.2.1980). Das der Öffentlichkeit im März präsentierte neue sozialpolitische Programm der Gewerkschaften orientiert sich explizit am Konzept der Statussicherung und fordert eine Anhebung des Rentensatzes auf 90 Prozent des Nettoeinkommens während der Erwerbstätigkeit (s. Süddeutsche Zeitung 12.3.1980).

Angesichts dieser diametral entgegengesetzten Vorstellungen und den ungünstigen Wirtschaftsprognosen für die kommenden Jahre erscheint ein Zerbröckeln des sozialpolitischen Konsensus der Nachkriegszeit nicht ausgeschlossen, und vielleicht ist es richtig, daß der Wohlfahrtsstaat selbst zunehmend vom Integrationselement zum politischen Spalter wird. Gegenwärtig bleibt allerdings festzuhalten, daß sich im diesjährigen Bundestagswahlkampf weder Biedenkopfs Privatisierungsvorstellungen noch Wehners Expansionspläne in der eigenen Partei durchsetzen konnten und daß die Sozialpolitik nicht zu einem umkämpften Kernthema der Wahl geworden ist. Die folgenden Abschnitte sollen in zusammenfassender Perspektive noch einmal die Konstellation der Makrogrößen diskutieren, welche die Grundlage für eine kommende Krise des Wohlfahrtsstaates abgeben könnte.

\section{Schlußfolgerungen und Ausblick}

Es kann als sicher gelten, daß der Wohlfahrtsstaat in der Bundesrepublik in den kommenden Jahren ernsthaften Belastungen ausgesetzt sein wird. Zunächst ist die deutsche Wirtschaft wegen ihrer export-intensiven Industrie und ihrer Abhängigkeit von Rohstoffimporten von Veränderungen der internationalen Austauschbedingungen zugunsten der Rohstoffproduzenten unmittelbar betroffen, so daß hohe Wachstumsraten in der Zukunft selbst dann gefährdet sein werden, wenn sich Theoreme einer Nachfragesättigung in post-industriellen Gesellschaften als zu pessimistisch erweisen sollten. Wachsende internationale Spannungen - etwa um knappe Rohstoffquellen entlang der West-Ost- wie der Nord-Süd-Achse - werden steigende Militärausgaben nach sich ziehen, die den für soziale Transferzahlungen zur Verfügung stehenden Anteil des öffentlichen Haushalts einengen. Der andauernde demographische Wandel wird den Anteil alter Menschen an der Bevölkerung, ungeachtet eines temporären Abbaus des Rentenbergs in den achtziger Jahren, auf hohem Niveau halten, und wenn die geburtenschwachen Jahrgänge der siebziger Jahre in den Arbeitsmarkt eintreten, wird sich die Relation zwischen Beitragszahlern und Leistungsempfängern in der Rentenversicherung gegen Ende des Jahrhunderts wieder zuspitzen. In ihrer Kombination werden diese Faktoren vermutlich ein weiteres Wachstum des Wohlfahrtsstaats als quasi-selbstverständliches Nebenprodukt des Wirtschafts-wachstums erschweren und eine stärkere Politisierung sozialpolitischer Fragen bewirken ${ }^{30}$.

„Politisierung“ und zunehmende Kontroversen müssen allerdings nicht notwendig mit wachsender politischer ,Spaltung“ gleichgesetzt werden. Konkurrierende Entwürfe können auch eine politische Ressource darstellen, da sie das innovative Potential für die Anpassung erstarrter institutioneller Strukturen an neue Herausforderungen erhöhen. Grundlegendere sozialpolitische Auseinandersetzungen stellen zumindest sicher, daß ein Faktor der in gegenwärtigen Theoremen häufig zur Begründung einer krisenhaften Entwicklung des Wohlfahrtsstaates herhält, nicht wirksam werden wird, nämlich die (vorgebliche) Tendenz demokratischer Parteien, sich im Buhlen um die Gunst des Wählers durch eine ständige Erhöhung des sozialen Konsums bis zum Ruin der Staatsfinanzen gegenseitig zu übertrumpfen ${ }^{31}$. Fünf weitere Überlegungen mögen

30 Einen sehr viel ausgearbeiteren Versuch der Kennzeichnung der Makro-Konstellation, der sich die westeuropäischen Wohlfahrtsstaaten in den kom. menden Jahren gegenübersehen werden, hat Peter Flora (1979) unternommen, auf dessen Überlegungen sich die Argumentation dieses Abschnittes stützt.

31 Das für die Bundesrepublik vermutlich herausragendste Beispiel für diese Tendenz war die in der Zeit wechselnder parlamentarischer Mehrheiten gemeinsam von CDU und SPD vorangetriebene Rentenreform von 1972. Vgl. dazu die zusammen- 
vielleicht zu einer Aufhellung des düsteren Krisenbildes von der Zukunft des Wohlfahrtsstaates beitragen.

(1) Die Elemente der möglicherweise kommenden Makrokonstellation - Rezession, internationale Spannungen, demographische Belastungen - müssen sich nicht notwendig additiv zu einer nicht mehr zu bewältigenden Problemsituation kumulieren, sondern können möglicherweise auch interaktiv auf eine Weise wirksam werden, die gewisse Probleme entschärft. So mag etwa die Knappheit von Stellen in einem schrumpfenden Arbeitsmarkt dazu beitragen, daß Frauen persönliche Erfuillung in stärkerem MaBe in der Mutterschaft als in der Erwerbstätigkeit suchen, was zu einer Reduzierung der demographisch bedingten Probleme der Rentenversicherung beitragen könnte. In ähnlicher Weise ist denkbar, daß erhöhte internationale Spannungen im Innern zur Erhöhung des Integrationsgrades und der Legitimität beitragen, insbesondere durch die Stärkung demokratischer kollektiver Ideale gegenüber der jüngeren Generation. Welche Auswirkungen die neue Makrokonstellation tatsächlich zeitigen wird, ist auf theoretischer Ebene allein nicht zu klären, sondern in erster Linie eine Frage an die empirische Forschung ${ }^{32}$.

(2) In der Vergangenheit hat die deutsche Sozialpolitik Probleme gemeistert, die bei Zugrundelegung des gegenwärtig gebrauchten Krisenstandards vermutlich als unlösbar bezeichnet worden wären. In den füfziger Jahren wurden inmitten verbreiteter Arbeitslosigkeit rund 10 Millionen Flüchtlinge - in allen Ländern ein bedeutsames Potential für revanchistische politische Positionen - in Staat und Gesellschaft der Bundesrepublik integriert. Die Wiederaufrüstung und die den Staatshaushalt belastende Schaffung der Bundeswehr waren 1957 von der Rentenreform und der größten Expansion der

fassende Gegenüberstellung der jeweiligen Expansionsvorstellungen - Stichworte: Babyjahr und Rentenniveausicherung - in Nieder (1972: bes. 35-41).

32 Es sollte nicht notwendig sein, darauf hinzuweisen, daß es sich bei den angedeuteten Möglichkeiten um wissenschaftlich zu klärende Problemstellungen, keineswegs um politische Rezepte handelt.
Sozialleistungen in der Nachkriegszeit gefolgt. In der Vergangenheit ist der Wohlfahrtsstaat sowohl in Prosperitäts- wie in Rezessionsjahren, während des Kalten Krieges wie während der Entspannung gewachsen. Er hat sukzessiv alte Leistungslücken aufgefüllt und neue Probleme aufgegriffen, sobald der beeindruckend flexible Mechanismus der Problemartikulation in einer Demokratie sie ins Licht öffentlicher Diskussion geriickt hat (z.B. Unfallverhütung, Rehabilitation, Bildungsexpansion).

(3) Die Grenzen einer tragbaren Steuerlast sind empirisch ebenso wenig erforscht wie die der Reformfähigkeit kapitalistischer Demokratien. Debatten um die Grenzen des Wachstums haben den Wohlfahrtsstaat seit seinen Anfängen im letzten Jahrhundert begleitet. Eine historische Bilanz der jeweils postulierten absoluten Ausdehnungsgrenzen würde vermutlich amüsante Resultate erbringen, denn die behaupteten Grenzen wurden meist schon nach wenigen Jahren durchbrochen ${ }^{33}$. Wo die Grenzen tatsächlich liegen, ist wahrscheinlich ebenso von der Fähigkeit der Regierungen abhängig, Unterstützung für die Sozialpolitik zu mobilisieren, wie von objektiven ökonomischen Faktoren.

(4) Das Potential für Reformen, die wenig oder gar nichts kosten, aber dennoch wirksam zur Erhöhung sozialer Sicherheit und Zufriedenheit beitragen, erscheint noch völlig unausgeschöpft. So stammt ein guter Teil der Unsicherheit über die Altersversorgung vermutlich aus der unzureichenden Information und der Undurchschaubarkeit des komplizierten Paragraphenwerkes. 1956 gaben z.B. 88 Prozent der Befragten einer Repräsentativerhebung an, daß sie nicht wußten, worum es bei der damals politisch diskutierten Rentenreform ging (Institut für Demoskopie 1957: 97) ${ }^{34}$, 1963 sagten 85 Prozent der Befrag-

33 Manfred Schmidt (1978) hat die Vorschriften der Arbeitsstättenverordnung zur Mindestgröße des Arbeitsraumes als Beispiel für das Übertreffen eines Grenzwertes geschildert, der von Marx im Kapital als unter kapitalistischen Bedingungen unerreichbar bezeichnet worden war (Schmidt 1978: 61). Eine systematische Untersuchung solcher Fehleinschätzungen der Vergangenheit wurde die Mühe sicher lohnen.

34 Die Zahl ergibt sich aus der Addition der Werte in zwei verschiedenen Tabellen. 72 Prozent ant- 
ten, sie hätten keine Vorstellung über die Höhe ihrer künftigen Rente (Kaufmann 1969: 108). Angesichts der Datenverarbeitungskapazitäten heutiger Bürokratien sollte es nicht schwerfallen, jedem Bürger jährlich einen verständlichen Bericht über seine Rentenanspruche zu schicken, der angibt, welche Beiträge bislang gezahlt wurden und in welche Leistungen sie sich umsetzen $^{35}$. Größere Zufriedenheit könnte z.B. durch kostenneutrale Reorganisationen der Arbeitswelt produziert werden; etwa, indem die Idee der gleitenden Arbeitszeit vom Tag auf den Zeitraum einer Woche, eines Jahres oder des gesamten Arbeitslebens ausgedehnt wird. Eine administrative Dezentralisierung, die den Kontakt zwischen Bürger und Sozialbürokratie verbessert, könnte möglicherweise die Effizienz der Systeme steigern, während eine größere Freiheit der Wahl von Risikoklassen auch in der Pflichtversicherung dem Bedürfnis nach individuellen Entscheidungen Rechnung tragen könnte.

(5) Sollte die angespannte Haushaltslage Leistungskürzungen tatsächlich erforderlich machen, so ist nicht einzusehen, warum sie vor der Öffentlichkeit nicht einsichtig begründbar sein sollten. Sicherlich waren versuchte Leistungsbeschränkungen in der Vergangenheit - etwa in der Rentendiskussion von 1976 - stets von massiven öffentlichen Protesten begleitet, aber die waren anscheinend in erster Linie ein Ausdruck der Enttäuschung früher gemachter Zusagen. Wenn die Politiker keine Versprechungen machen, die sie später nicht halten können, und die Gründe für ihre Sanierungsvorhaben öffentlich darlegen, können kostendämpfende Maßnahmen durchaus auf Zustimmung stoßen. 1978 meinten z.B. 71 Prozent der in einer Repräsentativerhebung Befragten insgesamt und immerhin 56 Prozent der Rentner, daß sie für reduzierte Zuwachsraten der Renten in den nächsten Jahren Verständnis hätten (Bundesministerium für Arbeit 1980: 68). Von ausschlaggebender Bedeutung mag allerdings sein, wie Kürzungen begründet und auf welche Weise sie realisiert werden. Bezüglich der Realisierungsweise gibt es unter-

worteten mit ,weiß nicht", 16 Prozent erklärten, Bescheid zu wissen, gaben aber auf Nachfrage unzutreffende Antworten.

$35 \mathrm{Vgl}$. die technische Ausarbeitung dieses Gedankens im Volksversicherungsplan der SPD, beschrieben in Bartholomäi (1977). schiedliche Grade der Sichtbarkeit von Kürzungsmaßnahmen. So ist die Senkung eines gesetzlich verankerten Leistungssatzes sicherlich sehr viel stärker sichtbar und angetan, Protest zu mobilisieren, als eine Änderung der diversen Leistungsvoraussetzungen. Bezüglich der Begründung wird die pragmatische Erklärung einer prekären Relation von steigenden Ausgaben und sinkenden Einnahmen vermutlich sehr viel eher akzeptiert als grundsätzliche Lobgesänge auf die Vorteile privater Hilfe gegenüber Staatshilfe und Warnungen vor einer sozialpolitischen Hängematte, die von arbeitsscheuen Müßiggängern mißbraucht werde. Diese letzte Lektion wurde in der Bundesrepublik auf eindrucksvolle Weise durch das Scheitern der Krankenversicherungsreformpläne der CDU in den fünfziger und sechziger Jahren gelehrt, die der Öffentlichkeit in sozialpädagogischer Verbrämung präsentiert wurden (s. Richter/Müller 1967).

Ein ideologischer Fundamentalangriff auf den Wohlfahrtsstaat würde fast mit Sicherheit massiven Widerstand wecken. Die Kritiker einer sozialstaatlichen Umverteilung sollten sich vor $\mathrm{Au}$ gen halten, daß ein Abbau der Sozialleistungen gegenüber dem gegenwärtig geltenden Distributionssystem selbst eine radikale Umverteilung bedeuten würde. Trotz der in historischer Perspektive beeindruckenden Verdreifachung der Reallöhne in der Bundesrepublik seit dem Zweiten Weltkrieg fühlt sich gegenwärtig nur eine Minderheit der Bürger bereits ,gut gesichert“ (38\% der Wahlbevölkerung, 35\% der Facharbeiter und 33\% der ungelernten Arbeiter - s. Bundesministerium für Arbeit 1980: 44). Für die große Mehrheit der Bevölkerung besteht die Sorge offensichtlich nicht darin, daß Grenzen des Wohlfahrtsstaates ereicht werden könnten, die die wirtschaftliche Entwicklungsfähigkeit oder die individuelle Freiheitssphäre bedrohen, sondern darin, daß ein Mindestmaß an sozialer Sicherung erreicht oder bewahrt wird. Wie erfolgreich dies in der Zukunft geleistet werden kann, ist nicht zuletzt davon abhängig, wie die verantwortlichen Kräfte die anstehenden Aufgaben definieren und wie sie die vorhandenen Kapazitäten des demokratischen Staates öffentlich einschätzen. Wiederholte Krisenprophezeiungen laufen die Gefahr, eine Krise herbeizureden, für die sich sonst bislang keine überzeugenden Anzeichen finden lassen. Nach dem Rückblick auf die letzten dreißig Jahre der Entwicklung der 
Sozialpolitik in der Bundesrepublik sehe ich keinen überzeugenden Grund, warum die anstehenden Probleme nicht ebenso durch institutionelle Reformen bewältigt werden sollten, wie die Herausforderungen der Vergangenheit.

\section{Anhangstabellen}

TABELLE A 1 Der ökonomische Kontext des Wachstums des Wohlfahrtsstaates in der Bundesrepublik (I)

\begin{tabular}{|c|c|c|c|c|c|c|}
\hline gahr & 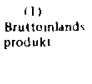 & $\begin{array}{l}121 \\
\text { Wathrum } \\
\text { rate }\end{array}$ & $\begin{array}{l}\text { 131 } \\
\text { Bruitowzisl } \\
\text { produkt in } \\
\text { kany Preiven } \\
119751\end{array}$ & 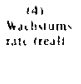 & $\begin{array}{c}\text { (5) } \\
\text { Brutitandage } \\
\text { mivestertionen }\end{array}$ & $\begin{array}{l}161 \\
\text { Wuehuem } \\
\text { rate }\end{array}$ \\
\hline \multicolumn{7}{|l|}{ 194\% } \\
\hline & 978 & & & & $|H|$ & \\
\hline 1951 & 1195 & 222 & & & 223 & $23:$ \\
\hline 1952 & $136 \mathrm{~s}$ & $1+2$ & & & 256 & 148 \\
\hline 1953 & 1470 & 77 & 3644 & & 291 & 177 \\
\hline 1954 & $15 B 2$ & 16 & 1902 & +1 & $32 \mathrm{~K}$ & 127 \\
\hline 1955 & 1808 & 143 & 4365 & 119 & $40 ?$ & $2+1$ \\
\hline 1956 & 1990 & 101 & 4660 & 64 & 448 & in $\mathrm{i}$ \\
\hline 1457 & 2164 & 87 & 4924 & 36 & 465 & 14 \\
\hline 1458 & $231 ?$ & $\begin{array}{l}81 \\
68\end{array}$ & $\begin{array}{l}428 \\
50888\end{array}$ & $\begin{array}{l}30 \\
3=\end{array}$ & 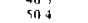 & 87 \\
\hline 1959 & $250 \mathrm{~d}$ & 83 & 5443 & 70 & 580 & 151 \\
\hline $\begin{array}{l}1960 \\
1960\end{array}$ & $\frac{3028}{3028}$ & $20 y_{1}$ & $5901) \overline{8}$ & 1861 & $\frac{380}{735}$ & $\prod_{1}=n_{1}$ \\
\hline 1960 & 3318 & 96 & 6197 & 49 & 834 & 135 \\
\hline 1962 & 3604 & as & 6470 & +4 & 929 & 114 \\
\hline 1963 & 3825 & 60 & 6663 & 30 & 977 & 52 \\
\hline 1964 & 4203 & 99 & 7109 & 66 & $111 ?$ & 143 \\
\hline 1965 & 4593 & 93 & $749 \mathrm{~B}$ & 55 & 1300 & 74 \\
\hline 1966 & 4483 & 63 & 7688 & 25 & 124 & 15 \\
\hline 1967 & 4945 & 13 & 7678 & 01 & 1142 & 81 \\
\hline 1968 & 5349 & 42 & $\$ 17 B$ & 63 & 1202 & 53 \\
\hline $\begin{array}{l}19689 \\
1969\end{array}$ & $\begin{array}{l}59740 \\
5970\end{array}$ & 116 & 8823 & 79 & 1396 & 161 \\
\hline 1970 & 6788 & 137 & 9342 & 59 & 1337 & 244 \\
\hline 1971 & 7549 & 112 & 9654 & 33 & 1996 & 149 \\
\hline 1972 & 8260 & 94 & 10006 & 36 & 2194 & 74 \\
\hline 1973 & 9186 & 112 & 10497 & 49 & 2255 & 52 \\
\hline 1974 & 9871 & 75 & 10534 & 04 & 2164 & 40 \\
\hline 1975 & 10328 & 46 & 10339 & 14 & $21+5$ & 09 \\
\hline 1976 & 11194 & 84 & 10866 & 51 & 2319 & 81 \\
\hline 1977 & 11935 & 66 & IIIA & 26 & 2491 & 14 \\
\hline 1978 & $1287 ?$ & 79 & 11519 & 34 & 276.5 & 180 \\
\hline
\end{tabular}

Quellen 111 (31 151 Imernational Monetary I und $11979 \quad 192 \quad 1931$ MTS DM 1960 Umtellung der tatnis hen

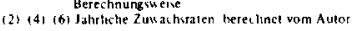

TABELLE A 2 Der ökonomische Hintergrund des Wachstums des Wohlfahrtsstaates in der Bundesrepublik (II)

\begin{tabular}{|c|c|c|c|c|c|}
\hline Jahr & $\begin{array}{l}\text { (1) } \\
\text { Zah! der Arbelts- } \\
\text { losen ( } 1000)\end{array}$ & $\begin{array}{l}\text { (2) } \\
\text { Arbestslosen- } \\
\text { quote (\% der } \\
\text { abhangigen } \\
\text { Erwerbsbe- } \\
\text { volkerung) }\end{array}$ & $\begin{array}{l}\text { (3) } \\
\text { Index der Ver- } \\
\text { brauche1 presse } \\
(1975=100)\end{array}$ & $\begin{array}{c}(4) \\
\text { Inflationsrate }\end{array}$ & $\begin{array}{l}\text { (5) } \\
\text { Offentiliche } \\
\text { Schulden } \\
\text { (Kreditf inan- } \\
\text { zierungsquote } \\
\text { in \%) }\end{array}$ \\
\hline 1949 & & & 509 & & \\
\hline 1950 & 1869 & 110 & 477 & -63 & 60 \\
\hline 1951 & 1714 & 104 & 514 & 23 & 35 \\
\hline 1952 & 1652 & 95 & 525 & 21 & 01 \\
\hline 1953 & 1491 & 8.4 & 515 & -19 & .08 \\
\hline 1954 & 1411 & 76 & 516 & 02 & -15 \\
\hline 1955 & 1074 & 56 & 525 & 17 & -50 \\
\hline 1956 & 876 & 44 & 538 & 25 & 22 \\
\hline 1957 & 754 & 37 & 549 & 20 & 65 \\
\hline 1958 & 764 & 37 & 561 & 22 & 55 \\
\hline 1959 & 540 & 26 & 566 & 09 & 24 \\
\hline 1960 & 271 & 13 & 575 & 16 & 14 \\
\hline 1961 & 181 & 08 & 588 & 23 & -03 \\
\hline 1962 & 155 & 07 & 606 & 3.1 & 17 \\
\hline 1963 & 187 & 08 & 62.4 & 29 & 46 \\
\hline 1964 & 169 & 08 & 638 & 2.3 & 48 \\
\hline 1965 & 147 & 07 & 659 & 3.3 & 73 \\
\hline 1966 & 161 & 07 & 682 & 3.6 & 59 \\
\hline 1967 & 459 & 21 & 693 & 16 & 87 \\
\hline 1968 & 323 & 15 & 705 & 16 & 46 \\
\hline 1969 & 178 & 09 & 318 & 19 & -14 \\
\hline 1970 & 149 & 07 & 742 & 34 & 42 \\
\hline 1971 & 185 & 09 & 782 & 53 & 68 \\
\hline 1972 & 246 & 11 & 825 & 55 & 56 \\
\hline 1973 & 273 & 13 & 882 & 69 & 32 \\
\hline 1974 & 582 & 2.6 & 944 & 70 & 85 \\
\hline 1975 & 1074 & 47 & 1000 & 60 & 178 \\
\hline 1976 & 1060 & 4.6 & 1045 & 45 & 132 \\
\hline 1977 & 1029 & 4.5 & 1086 & 39 & $B 8$ \\
\hline 1978 & $(1030)$ & 43 & 1114 & 26 & \\
\hline
\end{tabular}

Quellen (1). (2) 1950-1971 Stalist isches Bundesamt (1972 148) 1972-1978: Bundesmเ nisterium der Finanzen Finanzbericht (1975-1980), 1950-58 ohne Saarland.

(3) International Monetary Fund (1979 190-191)

(4) 1949-62: Vom Autor berechnete jahr hiche Zuwachstaten von (3), 1963 78: Sozlabericht $1978 \quad 324$

(5) Daten des HIWED Projektes, gesammelt von Jurgen Kohl foffent tuche Einnahmen - offenthche Ausgaben/of fentlyche Ausgaben, fur alle Gebictskorperschaften); Negativatilen zeugen Uberschusse an.
TABELLE A 3 Sozialausgaben in der Bundesrepublik

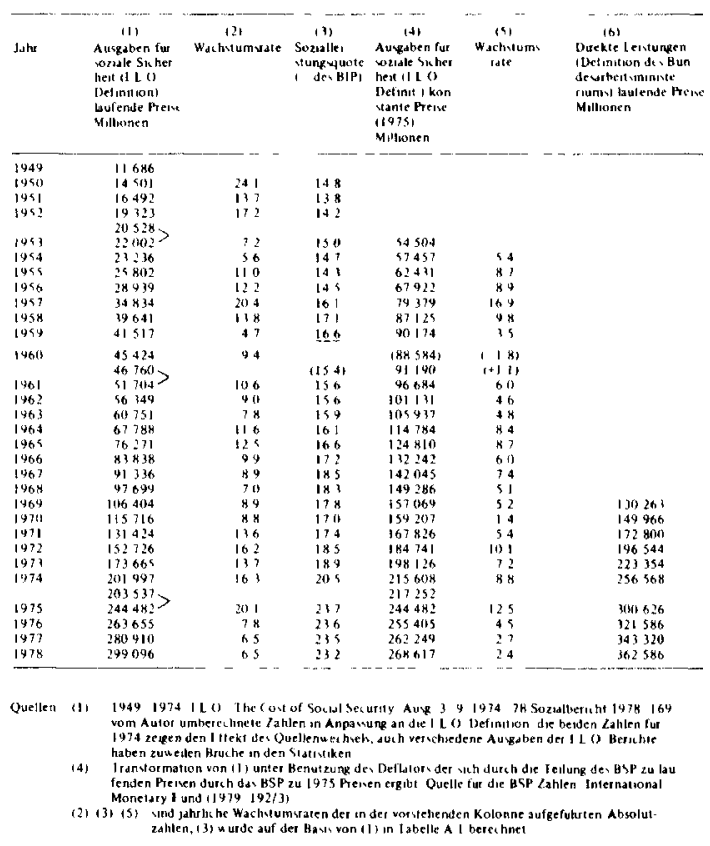

TABELLE A 4 Die Kosten der Sozialen Sicherung in der Bundesrupublik

\begin{tabular}{|c|c|c|c|c|c|}
\hline Jahu & $\begin{array}{l}\text { (1) } \\
\text { Durchsehnitts- } \\
\text { verdienst der be } \\
\text { schaftugten Arbett- } \\
\text { nehmer } \\
\text { (DM pro Monat) }\end{array}$ & $\begin{array}{l}\text { (2) } \\
\% \\
\text { Steuerabzug }\end{array}$ & $\begin{array}{l}\text { (3) } \\
\text { Soztalversi- } \\
\text { cherurigsbeitr age }\end{array}$ & $\begin{array}{l}(4) \\
\text { Lohnabzuge } \\
\text { insgesamt }\end{array}$ & $\begin{array}{l}\text { (5) } \\
\text { beitrag ssatze } \\
\text { der Sozialver } \\
\text { scherung ins } \\
\text { gesami }\end{array}$ \\
\hline 1950 & 243 & 46 & 79 & 125 & 10 \\
\hline 1951 & 283 & 61 & 78 & 139 & 10 \\
\hline 1952 & 305 & 68 & 77 & 145 & 10 \\
\hline 1953 & 323 & 62 & 79 & 142 & 10 \\
\hline 1954 & 340 & 60 & 78 & 139 & 101 \\
\hline 1955 & 377 & 63 & 78 & 141 & $10 i$ \\
\hline 1956 & 396 & 67 & 77 & 144 & 101 \\
\hline 1957 & 417 & 52 & 87 & 139 & 117 \\
\hline 1958 & 444 & 56 & 93 & 149 & 122 \\
\hline 1959 & 469 & 53 & 94 & 147 & 122 \\
\hline 1960 & 513 & 64 & 96 & 159 & 122 \\
\hline 1961 & 565 & 72 & 93 & 166 & 123 \\
\hline 1962 & 616 & 76 & 94 & 170 & 123 \\
\hline 1963 & 654 & 80 & 94 & 173 & 125 \\
\hline 1964 & 713 & 85 & 93 & 178 & 125 \\
\hline 1965 & 778 & 78 & 94 & 172 & 126 \\
\hline 1966 & 835 & 86 & 97 & 183 & 1265 \\
\hline 1967 & 862 & 88 & 99 & 186 & 127 \\
\hline 1968 & 916 & 94 & 103 & 197 & 1325 \\
\hline 1969 & 1000 & 103 & 107 & 210 & 139 \\
\hline 1970 & 1148 & 119 & 109 & 228 & 1325 \\
\hline 1971 & 1283 & 134 & 108 & 242 & 1325 \\
\hline 1972 & 1398 & 130 & 112 & 242 & 1355 \\
\hline 1973 & 1565 & 149 & 118 & 267 & 1445 \\
\hline 1974 & 1744 & 160 & 118 & 278 & 1460 \\
\hline 1975 & 1869 & 152 & 125 & 277 & 1525 \\
\hline 1976 & 1999 & 162 & 133 & 295 & 1615 \\
\hline 1977 & 2137 & 169 & 134 & 303 & 162 \\
\hline 1978 & 2255 & 164 & 134 & 297 & 162 \\
\hline
\end{tabular}

Quclken (1) Sozialbetichi 1978316 (Aggregatzahlen det volksw urtschaftlichen Gesamtrechnun ohne Arteitgeberbeitrage zur Sozatver sicherung)

(2), (3), (4) Sozialbericht 1978315 (Aggregalzahlen, ohne Arbeitgeberbetrage)

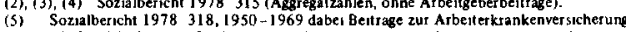
1970-1978 Beitr age für Arbeiter- und Angestellitenver sichcrung zusammen; die insttutonellen Bettragssatze sind wegen der Beturagsbemessungsgrenze hoher als die Prozentsatze der Aggregatzahlen in (3), dic in die Gesamtzahl eingegangenen Krankenverstcherungsbetuage sind Durchschnitissatze 


\section{Literatur:}

Achinger, H., 1971: Sozialpolitik als Gesellschaftspolitik. Von der Arbeiterfrage zum Wohlfahrtsstaat. Frankfurt: Eigenverlag des Deutschen Vereins für öffentliche und private Fürsorge.

Achinger, H., 1977: Altershilfe und Sozialversicherung S. 173-182 in: R. Bartholomäi/W. Bodenbender/ H. Henkel/R. Hüttel (Hrsg.), Sozialpolitik nach 1945. Bonn-Bad Godesberg: Verlag Neue Gesellschaft.

Alber, J., 1976: Participants of Social Insurance Systems in Western Europe. HIWED Report No. 4 Mannheim: vervielfältigt.

Alber, J., 1979: Die Entwicklung sozialer Sicherungssysteme im Licht empirischer Analysen. S. 123-211 in: H.F. Zacher (Hrsg.), Bedingungen für die Entstehung und Entwicklung von Sozialversicherung. Berlin: Duncker \& Humblot.

Badura, B./Gross, P., 1976: Sozialpolitische Perspektiven. München: Piper.

Baier, H., 1977: Herrschaft im Sozialstaat. Auf der Suche nach einem soziologischen Paradigma der Sozialpolitik. S. 128-142 in: C. von Ferber/F.-X. Kaufmann (Hrsg.), Soziologie und Sozialpolitik. Kölner Zeitschrift für Soziologie und Sozialpsychologie, Sonderheft 19. Opladen: Westdeutscher Verlag.

Baker, H.W., 1977: Beginn der deutschen Sozial- und Arbeitspolitik unter der Militärregierung. S. 23-31 in: R. Bartholomäi et al., 1977.

Ballerstedt, E./Glatzer, W., 1975: Soziologischer Almanach. Handbuch gesellschaftspolitischer Daten und Indikatoren für die Bundesrepublik Deutschland. Frankfurt: Campus.

Bank, H.P., 1970: Die Sozialgesetzgebung der Bundesrepublik Deutschland und ihr zeitlicher Zusammenhang mit den Wahlterminen seit 1949. Recht der Arbeit 23: $101-108$.

Bardens, H., 1977: Zur Nachkriegsentwicklung der Gesundheitspolitik. S. 295-302 in: R. Bartholomäi et al., 1977.

Bartholomäi, R., 1977: Der Volksversicherungsplan der SPD. S. 161-171 in: R. Bartholomäi et al., 1977.

Bartholomäi, R./Bodenbender, W./Henkel, H./Hüttel, R. (Hrsg.), 1977: Sozialpolitik nach 1945. Bonn-Bad Godesberg: Verlag Neue Gesellschaft.

von Bethusy-Huc, V., 1965: Das Sozialleistungssystem der Bundesrepublik Deutschland. Tübingen: Mohr.

von Beyme, K., 1979: Die großen Regierungserklärungen der deutschen Bundeskanzler von Adenauer bis Schmidt. München: Hanser.

Blind, A./von Ferber, C./Krupp, H.-J. (Hrsg.), 1969: Sozialpolitik und persönliche Existenz. Festgabe für Hans Achinger. Berlin: Duncker \& Humblot.

Boettcher, E. (Hrsg.), 1957: Sozialpolitik und Sozialreform. Tübingen: Mohr.

Braun, H., 1972: Soziale Sicherung. System und Funktion. Stuttgart: Kohlhammer.

Briggs, A., 1961: The Welfare State in Historical Perspective. Europäisches Archiv für Soziologie 2: $221-258$.

Brück, G.W./Eichner, H., 1974: Perspektiven der Sozialpolitik. Göttingen: Schwartz.
Bundesministerium für Arbeit und Sozialordnung, 1977 : Übersicht über die soziale Sicherung. Bonn. (Frühere Ausgaben 1974, 1970, 1967, 1964, 1962, 1960, 1958, 1956).

Bundesministerium für Arbeit und Sozialordnung, 1978: Sozialbericht 1978. Bonn. (Frühere hier gebrauchte Ausgaben 1976, 1973, 1972).

Bundesministerium für Arbeit und Sozialordnung, 1980: Bürger und Sozialstaat. Forschungsbericht No. 22 von Infratest Sozialforschung im Auftrag des Bundesministeriums für Arbeit und Sozialordnung. Bonn.

Bundesministerium der Finanzen, 1979: Finanzbericht 1980. Bonn: Heger.

Eilers, E./Schanzenbach, M., 1977: Zur Nachkriegsgeschichte der Familienpolitik aus sozialdemokratischer Sicht. S. 229-238 in: R. Bartholomäi et al., 1977.

Farthmann, F., 1977: Entwicklungen im Tarifrecht der Nachkriegszeit. S. 441-457 in: R. Bartholomäi et al., 1977.

Fenner, C./Heyder, U./Strasser, J. (Hrsg.), 1978: Unfähig zur Reform? Köln/Frankfurt: Europäische Verlagsanstalt.

von Ferber, C., 1967: Sozialpolitik in der Wohlstandsgesellschaft. Hamburg: Wegner.

von Ferber, C., 1971: Gesundheit und Gesellschaft. Haben wir eine Gesundheitspolitik? Stuttgart: Kohlhammer.

von Ferber, C./Kaufmann, F.X., 1977: Soziologie und Sozialpolitik. Kölner Zeitschrift für Soziologie und Sozialpsychologie, Sonderheft 19. Opladen: Westdeutscher Verlag.

Fitting, K., 1977: Die Entwicklung der Mitbestimmung. S. 371-389 in: R. Bartholomäi et al., 1977.

Flora, P., 1977: Emile Durkheim and the Welfare State. Beitrag zur gemeinsamen Arbeitstagung der Social Policy Group und des HIWED-Projektes "The Historical Development and Current Problems of the Welfare States". Luzern. Vervielfältigt.

Flora, P./Alber, J./Kohl, J., 1977: Zur Entwicklung der westeuropäischen Wohlfahrtsstaaten. Politische Vierteljahresschrift 18: 707-772.

Flora, P., 1979: Krisenbewältigung oder Krisenerzeugung? Der Wohlfahrtsstaat in historischer Perspektive. S. 82-136 in: J. Matthes (Hrsg.), Sozialer Wandel in Westeuropa. Verhandlungen des 19. Deutschen Soziologentages Berlin 1979. Frankfurt: Campus.

Flora, P./Heidenheimer, A.J. (Hrsg.), 1980: The Development of Welfare States in Europe and North America. New Brunswick: Transaction. (Im Druck).

Geißler, H., 1976: Die Neue Soziale Frage. Freiburg: Herder.

Gladen, A., 1974: Geschichte der Sozialpolitik in Deutschland. Wiesbaden: Steiner.

Glatzer, W., 1977a: Einkommenspolitische Zielsetzungen und Einkommensverteilung. S. 223-284 in: W. Zapf (Hrsg.), Lebensbedingungen in der Bundesrepublik Deutschland 1950-1975. Frankfurt: Campus.

Glatzer, W., 1977b: Ziele, Standards und Soziale Indikatoren für die Wohnungsver sorgung. S. 467-566 in: W. Zapf, 1977. 
Glombig, E., 1977: Die Rehabilitation in der deutschen Nachkriegsgeschichte. S. 211-227 in: R. Bartholomäi et al., 1977.

Grosser, A., 1970: Deutschlandbilanz. München: Hanser.

Grube, F./Richter, G., 1977: Der SPD-Staat. München: Piper.

Hartwich, H.-H., 1978: Sozialstaat spostulat und gesellschaftlicher status quo. Opladen: Westdeutscher Verlag.

Heclo, H., 1980: Toward a new welfare state? Im Druck in: P. Flora/A.J. Heidenheimer (Hrsg.), 1980.

Heidenheimer, A.J./Heclo, H./Teich Adams, C., 1975 Comparative Public Policy. New York: St. Martin.

Helberger, C., 1977: Ziele und Ergebnisse der Gesundheitspolitik in der Bundesrepublik Deutschland. S. 567-631 in: W. Zapf, 1977.

Hensen, H., 1977: Zur Geschichte der Rentenfinanzen. S. 137-149 in: R. Bartholomäi et al, 1977.

Holler, A., 1977: Die Entwicklung der sozialen Krankenversicherung. S. 303-314 in: R. Bartholomäi et al., 1977.

Hondrich, K.O., 1979: Der Wohlfahrtsstaat und die Konstitution sozialer Probleme. S. 791-808 in: J. Matthes (Hrsg.), 1977.

Illich, I., 1977: Die Nemesis der Medizin. Hamburg.

I.L.O., 1955: The Cost of Social Security 1949-1951. Genf: International Labour Office.

I.L.O., 1958: The Cost of Social Security 1949-1954. Genf: International Labour Office.

I.L.O., 1961: The Cost of Social Security 1949-1957. Genf: International Labour Office.

I.L.O., 1964: The Cost of Social Security 1958-1960. Genf: International Labour Office.

I.L.O., 1967: The Cost of Social Security 1961-1963. Genf: International Labour Office.

I.L.O., 1972: The Cost of Social Security 1964-1966. Genf: International Labour Office.

I.L.O., 1976: The Cost of Social Security 1967-1971. Genf: International Labour Office.

I.L.O., 1978: The Cost of Social Security 1972-1974. Genf: International Labour Office.

Institut für Demoskopie, 1956: Jahrbuch der Öffentlichen Meinung 1947-1955. Allensbach: Institut für Demoskopie.

Institut für Demoskopie, 1957: Jahrbuch der Öffentlichen Meinung 1957. Allensbach: Institut für Demoskopie.

Institut für Demoskopie, 1965: Jahrbuch der Öffentlichen Meinung 1958-1964. Allensbach: Institut für Demoskopie.

Institut für Demoskopie, 1967: Jahrbuch der Öffentlichen Meinung 1965-1967. Allensbach: Institut für Demoskopie.

Institut für Demoskopie, 1974: Jahrbuch der Öffentlichen Meinung 1968-1973. Allensbach: Institut für Demoskopie.

Institut für Demoskopie, 1976: Allensbacher Jahrbuch der Demoskopie 1976. Wien/München/Zürich: Molden.

International Monetary Fund, 1979: International Financial Statistics Yearbook. Washington D.C.: International Monetary Fund.

I.V.S.S., 1959: Entwicklung und Tendenzen der sozialen Sicherheit, Band 2. Bundesrepublik Deutschland.
Genf: Internationale Vereinigung für soziale Sicherheit.

Janowitz, M., 1976: Social Control of the Welfare State. New York: Elsevier.

Jantz, K./Neumann-Duesberg, H./Schewe, D. (Hrsg.), 1959: Sozialreform und Sozialrecht. Festschrift für Walter Bogs. Berlin: Duncker \& Humblot.

Kaack, H., 1971: Geschichte und Struktur des deutschen Parteiensystems. Opladen: Westdeutscher Verlag.

Kaase, M./von Beyme, K. (Hrsg.), 1978: Elections \& Parties. London: Sage Publications.

Kaim-Caudle, P.R., 1973: Comparative Social Policy and Social Security. London: Martin Robertson.

Kaufmann, F.-X., 1969: Reaktionen und Motivationen der Bevölkerung gegenüber sozialpolitischen Umverteilungsmaßnahmen. Materialien aus der empirischen Sozialforschung, Heft 8 . Dortmund: Sozialforschungsstelle an der Univesität Münster.

Kaufmann, F.-X., 1973: Sicherheit als soziologisches und sozialpolitisches Problem. Stuttgart: Enke.

Klanberg, F., 1978a: Armut und ökonomische Ungleichheit in der Bundesrepublik Deutschland. Frankfurt: Campus.

Klanberg, F., 1978b: Materielle Armut in Perspektive. S. 113-158 in: H.J. Krupp/W. Glatzer (Hrsg.), Umverteilung im Sozialstaat. Frankfurt: Campus.

Kleinhenz, G./Lampert, H., 1971: Zwei Jahrzehnte Sozialpolitik in der BRD. Eine kritische Analyse. Ordo, Jahrbuch für die Ordnung von Wirtschaft und Gesellschaft 22: 103-158.

Klingemann, H.D./Taylor, C.L., 1978: Partisanship, Candidates and Issues: Attitudional Components of the Vote in West German Federal Elections. S. 97-133 in: M. Kaase/K. von Beyme (Hrsg.), Elections \& Parties. London: Sage Publications.

Köllermann, H.W., 1971 : Sozialpolitik in Deutschland - eine geschichtliche und systematische Einfürung. Stuttgart: Kohlhammer.

Könen, W., 1977: Der Weg zur Sozialhilfe. S. 401-411 in: R. Bartholomäi et al., 1977.

Kohl, J., 1980: Trends and problems in post-war public expenditure development in Western Europe and North America. Im Druck in: P. Flora/A.J. Heidenheimer (Hrsg.), 1980.

Korspeter, L./Haack, W., 1977: Politik für Vertriebene, Flüchtlinge, Kriegsgeschädigte, Heimkehrer, politische Häftlinge und Aussiedler. S. 275-293 in: R. Bartholomäi et al., 1977.

Kortmann, K., 1976: Zur Armutsdiskussion in der Bundesrepublik Deutschland. SPES Arbeitspapier Nr. 50 Frankfurt: vervielfältigt.

Külp, B./Schreiber, W. (Hrsg.), 1971: Soziale Sicherheit. Köln: Kiepenheuer \& Witsch.

Lepsius, M.R., 1979: Soziale Ungleichheit und Klassenstrukturen in der Bundesrepublik Deutschland. S. 166-209 in: H.-U. Wehler (Hrsg.), Klassen in der europäischen Sozialgeschichte. Göttingen: Vandenhoeck/Ruprecht.

Mackie, T.T./Rose, R., 1974: The International Almanac of Electoral History. London: Macmillan.

Matthes, J. (Hrsg.), 1979: Sozialer Wandel in Westeuropa. Verhandlungen des 19. Deutschen Soziologentages Berlin 1979. Frankfurt: Campus.

Müller, W./Neusüß, C., 1970: Die Sozialstaatsillusion 
und der Widerspruch von Lohnarbeit und Kapital. Sozialistische Politik 2: 4-71.

Muhr, G., 1977: Sozialpolitik der Nachkriegszeit - Betrachtungen aus der Sicht des DGB. S. 477-487 in: R. Bartholomäi et al., 1977.

Murswieck, A. (Hrsg.), 1976: Staatliche Politik im Sozialsektor. München: Piper.

Narr, W.-D./Offe, C. (Hrsg.), 1976: Wohfahrtsstaat und Massenloyalität. Köln: Kiepenheuer \& Witsch.

Nieder, K., 1972: Zur Sozialpolitik in der 6. Legislaturperiode des Deutschen Bundestages. S. 28-43 in: Institut für Politikwissenschaft der Universität Münster (Hrsg.), Wahl 72. Opladen: Westdeutscher Verlag.

Offe, C., 1972: Politische Herrschaft und Klassenstrukturen. Zur Analyse spätkapitalistischer Gesellschaftssysteme. S. 135-164 in: G. Kress/D. Senghaas, Politikwissenschaft. Eine Einführung. Frankfurt: Fischer.

Pappi, F.U., 1976: Einstellungen zum Wohlfahrtsstaat. S. 213-218 in: W. Zapf 1976.

Peschke, P., 1962: Geschichte der deutschen Sozialversicherung. Berlin (Ost): Tribüne.

Peters, H., 1959: Die Geschichte der Sozialversicherung. Bad Godesberg: Asgard.

Raschke, J. (Hrsg.), 1978: Die politischen Parteien in Westeuropa. Hamburg: Rowohlt.

Richter,-M./Müller, A., 1967: Kampf um die Krankenversicherung 1955-1965. Bad Godesberg: Verlag der Ortskrankenkassen.

Richter, M. (Hrsg.), 1970: Sozialreform. Dokumente und Stellungnahmen. Loseblattsammlung 19551970. Bonn: Asgard.

Rimlinger, G.V., 1971: Welfare Policy and Industrialization in Europe, America, and Russia. New York: John Wiley.

Roth, J., 1974: Armut in der Bundesrepublik. Frankfurt: Fischer.

Ruf, T., 1977: Zur Geschichte der Vermögenspolitik nach dem Krieg. S. 427-440 in: R. Bartholomäi et al., 1977.

Schelsky, H., 1978: Der selbständige und der betreute Mensch. Frankfurt: Ullstein.

Schewe, D., 1977: Von der ersten zur zweiten Rentenreform 1957-1976 - Die Entwicklung der Gesetzgebung über die Rentenversicherung. S. 183-190 in: R. Bartholomäi et al., 1977.

Schmidt, A., 1977: Zum Entstehen der Selbstverwaltung in der Nachkriegszeit - Rückblick aus gewerkschaftlicher Sicht. S. $391-400$ in: R. Bartholomäi et al., 1977.

Schmidt, M.G., 1978: Die „Politik der inneren Reformen" in der Bundesrepublik Deutschland seit 1969.

S. 30-81 in: C. Fenner et al. (Hrsg.), 1980.

Schüssler, H., 1977: Bedeutung und Stellenwert des Arbeitsschutzes im sozialpolitischen Kräftespiel der Bundesrepublik nach 1945. S. 315-323 in: R. Bartholomäi et al., 1977.

Spitaels, G./Klaric, D./Lambert, S./Lefevère, G., 1971: Les salaire indirect et la couverture des besoins sociaux, Vol. 3: La comparaison internationale Allemagne - France - Italie - Pays Bas. Brüssel: Université Libre.

Spitzmüller, K., 1977: Reform der Unfallversicherung.
S. 325-338 in: R. Bartholomäi et al., 1977.

Standfest, E., 1977: Sozialpolitik und Selbstverwaltung. WSI-Studien zur Gesellschafts- und Sozialforschung No. 35. Köln: Bund-Verlag.

Standfest, E., 1979: Sozialpolitik als Reformpolitik. WSI-Studien zur Gesellschafts- und Sozialforschung No. 39. Köln: Bund-Verlag.

Statistisches Bundesamt, 1972: Bevölkerung und Wirtschaft 1872-1972. Stuttgart: Kohlhammer.

Stingl, J., 1977: Vom Gesetz über Arbeitsvermittlung und Arbeitslosenversicherung (AVAVG) zum Arbeitsförderungsgesetz (AFG). S. $349-359$ in: R. Bartholomäi et al., 1977.

Strasser, J., 1978: Grenzen des Sozialstaats oder Grenzen kompensatorischer Sozialpolitik. S. 110-146 in: C. Fenner et al., 1978.

Strasser, J., 1979: Grenzen des Sozialstaats. Köln/ Frankfurt: Europäische Ver lagsanstalt.

Sund, O., 1977: Die Entwicklung des Rechtsanspruches in der sozialpolitischen Nachkriegsgeschichte. S. 151-160 in: R. Bartholomäi et al., 1977.

Tennstedt, F., 1976: Sozialgeschichte der Sozialversicherung. S. 385-492 in: M. Blohmke/C. von Ferber/K.P. Kisker/H. Schaefer (Hrsg.), Handbuch der Sozialmedizin Band 3: Sozialmedizin in der Praxis. Stuttgart: Enke.

Trometer, L., 1977: Die Kriegsopferversorgung nach 1945. S, 191-205 in: R. Bartholomäi et al., 1977.

U.S.H.E.W., 1977: Social Security Programs Throughout the World. Washington D.C.: U.S. Department of Health, Education and Welfare. (Erscheint nach früheren unregelmäßigen Ausgaben zwei-jährlich seit 1967).

Widmaier, H.P., 1976: Sozialpolitik im Wohlfahrtsstaat. Hamburg: Rowohlt.

Wilensky, H.L., 1975: The Welfare State and Equality. Berkeley: University of California Press.

Wilensky, H.L., 1976: The ,New Corporatism“, Centralization and the Welfare State. Beverly Hills: Sage.

Wilensky, H.L., 1980: Leftism, Catholicism and Democratic Corporatism: The Role of Political Parties in Recent Welfare State Development. Im Druck in: P. Flora/A. Heidenheimer (Hrsg.), 1980.

Zapf, W. (Hrsg.), 1976: Probleme der Modernisierungspolitik. Mannheim: Institut für Sozialwissenschaften.

Zapf, W., (Hrsg.), 1977: Lebensbedingungen in der Bundesrepublik Deutschland 1950-1975. Frankfurt: Campus.

Zapf, W., 1978: Modernization and Welfare Development: The Case of Germany. Beitrag zur Arbeitsgruppe Nr. 4, IX. Weltkongreß der Soziologie. Uppsala. Vervielfältigt.

Zöllner, D., 1963: Öffentliche Sozialleistungen und wirtschaftliche Entwicklung. Berlin: Duncker \& Humboldt.

Zöllner, D., 1970: Die soziale Gesetzgebung der Bundesrepublik Deutschland. Bonn: Asgard.

Zöllner, D., 1980: Hundert Jahre Sozialversicherung. In: H.F. Zacher (Hrsg.), Schriftenreihe für internationales und vergleichendes Sozialrecht. Band 5. Berlin: Duncker \& Humblot. (Im Druck). 